ARTICLE

https://doi.org/10.1038/s41467-019-11848-9

\title{
Highly efficient decomposition of ammonia using high-entropy alloy catalysts
}

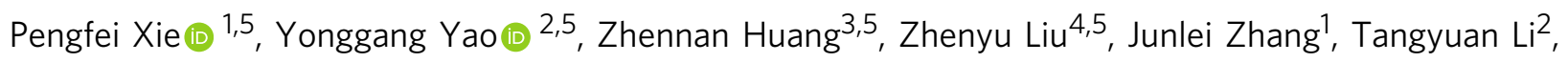
Guofeng Wang ${ }^{4}$, Reza Shahbazian-Yassar (i) ${ }^{3}$, Liangbing Hu (i) ${ }^{2} \&$ Chao Wang (i) ${ }^{1}$

Ammonia represents a promising liquid fuel for hydrogen storage, but its large-scale application is limited by the need for precious metal ruthenium $(\mathrm{Ru})$ as catalyst. Here we report on highly efficient ammonia decomposition using novel high-entropy alloy (HEA) catalysts made of earth abundant elements. Quinary CoMoFeNiCu nanoparticles are synthesized in a single solid-solution phase with robust control over the $\mathrm{Co} / \mathrm{Mo}$ atomic ratio, including those ratios considered to be immiscible according to the Co-Mo bimetallic phase diagram. These HEA nanoparticles demonstrate substantially enhanced catalytic activity and stability for ammonia decomposition, with improvement factors achieving $>20$ versus Ru catalysts. Catalytic activity of HEA nanoparticles is robustly tunable by varying the $\mathrm{Co} / \mathrm{Mo}$ ratio, allowing for the optimization of surface property to maximize the reactivity under different reaction conditions. Our work highlights the great potential of HEAs for catalyzing chemical transformation and energy conversion reactions.

\footnotetext{
${ }^{1}$ Department of Chemical and Biomolecular Engineering, Johns Hopkins University, Baltimore, MD 21218, USA. ${ }^{2}$ Department of Materials Science and Engineering, University of Maryland, College Park, MD 20742, USA. ${ }^{3}$ Department of Mechanical and Industrial Engineering, University of Illinois, Chicago, IL 60607, USA. ${ }^{4}$ Department of Mechanical Engineering \& Materials Science, University of Pittsburgh, Pittsburgh, PA 15261, USA. ${ }^{5}$ These authors contributed equally: Pengfei Xie, Yonggang Yao, Zhennan Huang, Zhenyu Liu. Correspondence and requests for materials should be addressed to G.W. (email: guw8@pitt.edu) or to R.S.-Y. (email: rsyassar@uic.edu) or to L.H. (email: binghu@umd.edu) or to C.W. (email: chaowang@jhu.edu)
} 
T he ammonia $\left(\mathrm{NH}_{3}\right)$ decomposition reaction has received increasing attention for the potential use of $\mathrm{NH}_{3}$ as a hydrogen storage medium ${ }^{1,2} . \mathrm{NH}_{3}$ can be readily liquefied at a mild pressure of $\sim 8$ bar at room temperature, giving rise to an energy density of $4.25 \mathrm{kWh} / \mathrm{L}$. Ruthenium $(\mathrm{Ru})$ has been known as the most active metal for catalyzing the decomposition of ammonia, but its large-scale application is limited due to the scarcity and high cost of this precious metal ${ }^{3-5}$. Literature efforts have thus turned to alloys of earth-abundant elements ${ }^{5-9}$. In particular, bimetallic Co-Mo has been shown to be promising for ammonia decomposition, as rationalized by the computational interpolation of adsorption properties on the alloy surfaces with mixed sites ${ }^{9,10}$. However, the functional tuning and catalytic activity of Co-Mo catalysts are largely constrained by the large miscibility gap present in the phase diagram of this binary alloy (Fig. 1), and the experimental studies have primarily been limited to the catalysts with elemental ratio of $\mathrm{Co} / \mathrm{Mo}$ around one $\mathrm{e}^{11-15}$. How to overcome this hurdle is of great interest for both fundamental understanding of alloy catalysts and pratical improvement of the performance of earth-abundant materials in energyconversion systems.

Here we report on a new class of high-entropy alloy (HEA) catalysts made of earth-abundant elements for highly efficient decomposition of ammonia. Enabled by a carbothermal shock technique, we have been able to grow HEA nanoparticles with five metals incorporated into a single solid-solution phase. We demonstrate breaking the miscibility limitation in bimetallic $\mathrm{Co}-$ Mo alloys by robustly tuning the $\mathrm{Co} / \mathrm{Mo}$ element ratio in $\mathrm{CoMoFeNiCu}$ HEA nanoparticles (Fig. 1). These HEA nanoparticles are subjected to systematic and comprehensive catalytic studies for the $\mathrm{NH}_{3}$ decomposition and compared to bimetallic $\mathrm{Co}-\mathrm{Mo}$ and monometallic Ru catalysts. A series of characterization techniques including atomically resolved scanning transmission electron microscopy (STEM), X-ray photoemission spectroscopy (XPS), and surface-specific temperature programmed desorption of nitrogen (nitrogen TPD) is employed to evaluate the structure-property relationship of the HEA catalysts.



The obtained knowledge is further integrated with the measured reaction kinetics and simulated atomic structures of the HEA catalysts to understand the catalytic enhancement mechanisms.

\section{Results}

Synthesis and characterization of HEA nanoparticles. The CoMoFeNiCu HEA nanoparticles were synthesized by employing flash heating and cooling of metal precursors on oxygenated carbon supports, with the temperature going up to $2000-2300 \mathrm{~K}$, the temperature ramping rate on the order of $10^{5} \mathrm{~K} \mathrm{~s}^{-1}$ and the duration of shocks as short as $\sim 55 \mathrm{~ms}$ (Fig. $2 \mathrm{a}-\mathrm{c})^{16}$. Under such conditions, the high temperature induced rapid thermaldecomposition of the precursors, forming small liquid droplets of multimetallic solutions. The subsequent rapid cooling enabled crystallization of these liquid droplets into uniform and homogeneous alloy nanoparticles without being subjected to aggregation/agglomeration, element segregation or phase separation. Five types of HEA nanoparticles with the general composition $\mathrm{Co}_{x-}$ $\mathrm{Mo}_{y} \mathrm{Fe}_{10} \mathrm{Ni}_{10} \mathrm{Cu}_{10}(x+y=70)$ were prepared by using this method, in which the atomic ratio of Co/Mo was controlled to be $15 / 55,25 / 45,35 / 35,45 / 25$, and $55 / 15$ by varying the loading of precursors, the overall loading of metals in each catalyst was controlled at $10 \mathrm{wt} \%$ during synthesis. These nanoparticles are denoted as HEA-Co $\mathrm{Co}_{y}$ (e.g., HEA-Co ${ }_{15} \mathrm{Mo}_{55}$ for $\mathrm{Co}_{15} \mathrm{Mo}_{55^{-}}$ $\left.\mathrm{Fe}_{10} \mathrm{Ni}_{10} \mathrm{Cu}_{10}\right)$ in the following discussion. Bimetallic Co-Mo and monometallic $\mathrm{Ru}$ nanoparticles were also synthesized using the same method with similar metal loadings, which served as control in this study.

Figure $2 \mathrm{~d}$ shows representative scanning electron microscopy (SEM) images of the $\mathrm{C}_{25} \mathrm{Mo}_{45} \mathrm{Fe}_{10} \mathrm{Ni}_{10} \mathrm{Cu}_{10}$ nanoparticles uniformly dispersed on the carbon nanofibers (see more images in Supplementary Fig. 1). The spacing between neighboring nanoparticles varies from $\sim 10$ to $\sim 100 \mathrm{~nm}$. The average particle size is measured to be $\sim 22 \mathrm{~nm}$ from the transmission electron microscopy (TEM) images (Fig. 2e, f; also see more images in Supplementary Fig. 2). Low- and high-magnification elemental maps depict homogeneous distribution of all the five elements

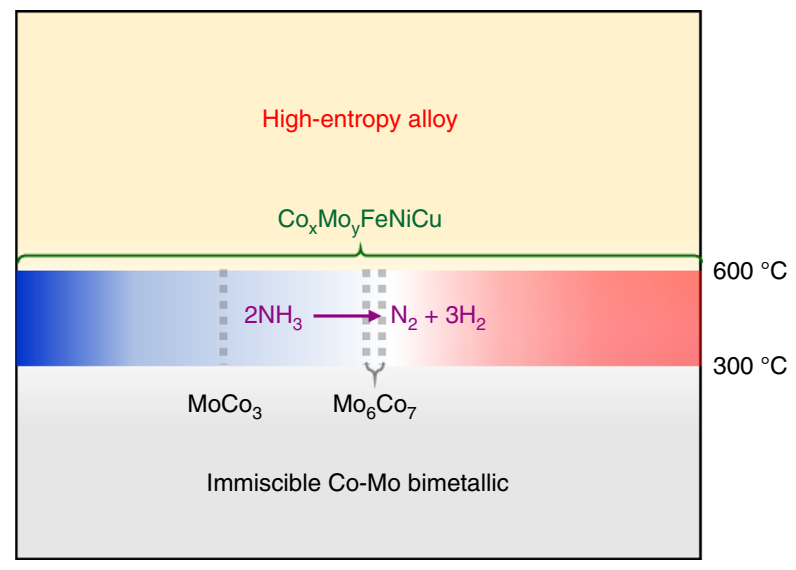

Co

Mo

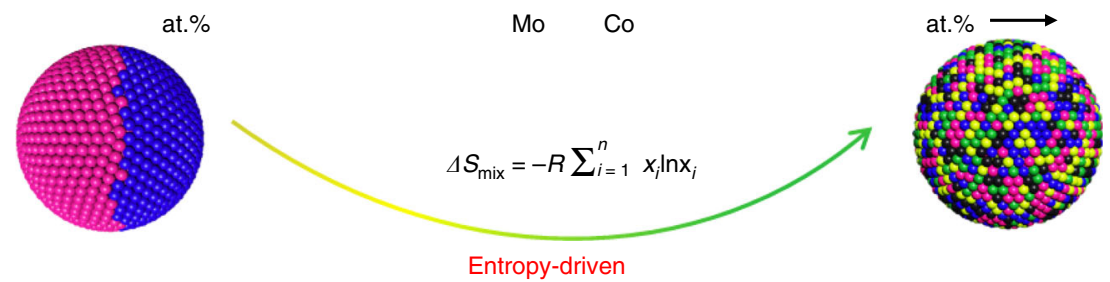

Fig. 1 HEA catalysts breaking the miscibility limitation of conventional binary alloys. The phase diagram of bimetallic Co-Mo (left) is reprinted from Wang et al. ${ }^{51}$, with permission from Elsevier 




During shock
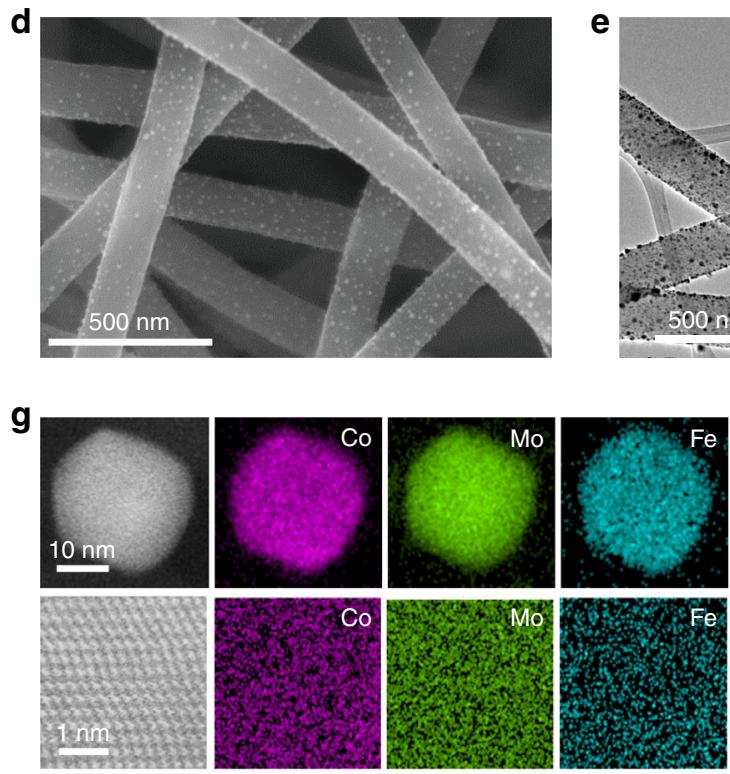

b
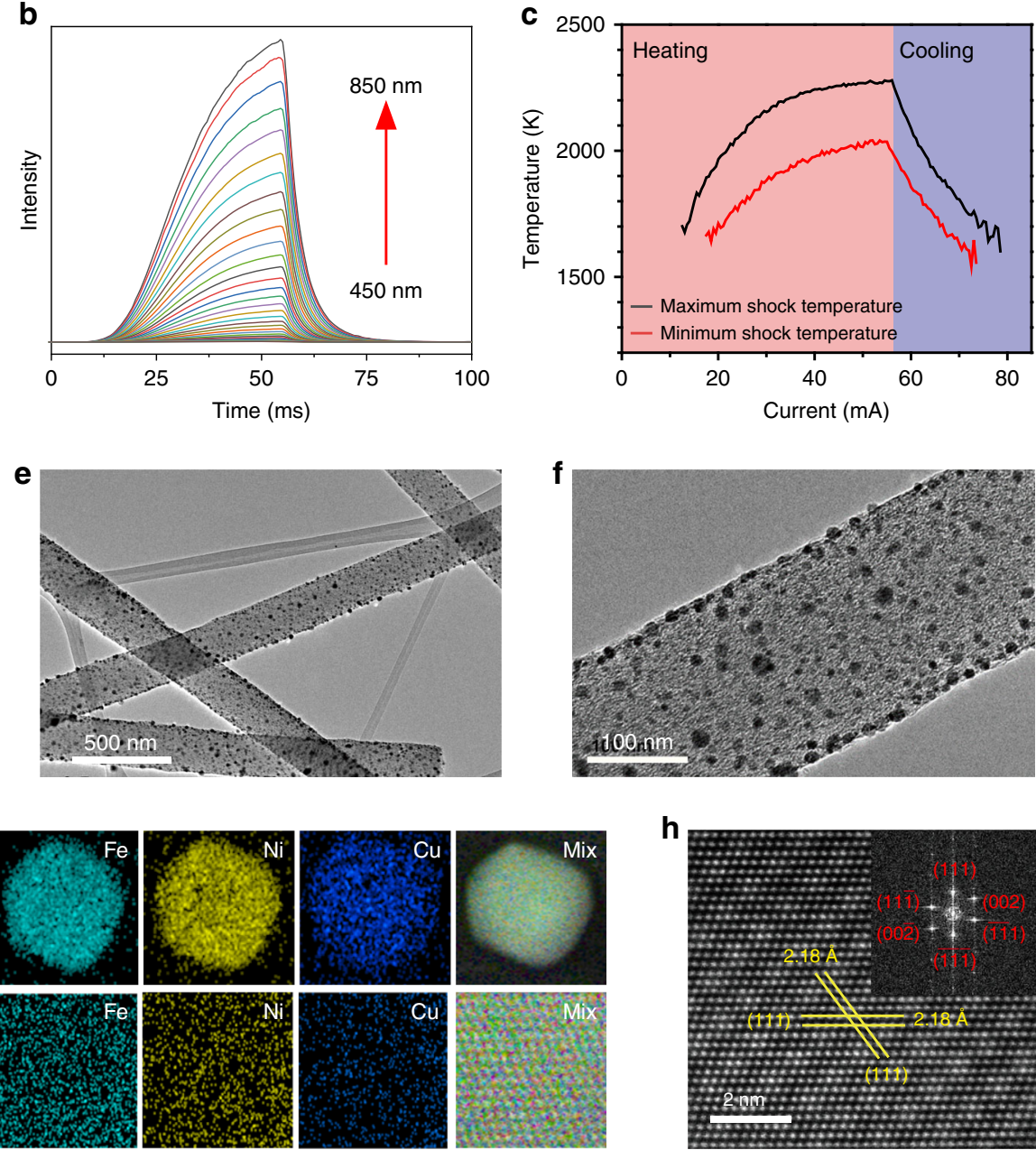

Fig. 2 High-entropy alloy CoMoFeCoNi $\left(\mathrm{HEA}-\mathrm{Co}_{x} \mathrm{Mo}_{y}\right)$ nanoparticles. a Digital images of the samples before and during the thermal shock synthesis. $\mathbf{b}$ Intensity of the emitted light from the shock at different wavelengths. c Typical temperature profiles during the thermal shocks as determined from the emission intensities. d Representative SEM and e, $\mathbf{f}$ TEM images of the obtained HEA nanoparticles well dispersed on carbon nanofibers (CNFs). $\mathbf{g}$ STEMbased elemental maps of the HEA-CO${ }_{25} \mathrm{Mo}_{45}$ nanoparticles at low- (upper panel) and high- (lower panel) resolutions. $\mathbf{h}$ High-resolution HAADF-STEM image with the fast Fourier transform (FFT) pattern indicating an fcc crystal structure

throughout the $\mathrm{C}_{25} \mathrm{Mo}_{45} \mathrm{Fe}_{10} \mathrm{Ni}_{10} \mathrm{Cu}_{10}$ nanoparticles (Fig. $2 \mathrm{~g}$ and Supplementary Fig. 3), and similar observations were also obtained on the HEA nanoparticles of different compositions (Supplementary Figs. 4-7). In contrast, the bimetallic $\mathrm{Co}_{36} \mathrm{Mo}_{64}$ nanoparticles (corresponding to $\mathrm{Co} / \mathrm{Mo}=25 / 45$ ) show separated Co- and Mo-rich phases (Supplementary Fig. 8), as this composition falls into the miscibility gap in the corresponding binary phase diagram (Fig. 1). Atomically resolved high-angle annular dark-field scanning TEM (HAADF-STEM) imaging and the corresponding fast Fourier transform analysis reveal a facecentered cubic $(f c c)$ phase for the HEA nanoparticles, with the inter-plane spacing measured to be $2.18 \AA$ for the (111) lattice fringes (Fig. 2h).

Crystal structure of the HEA nanoparticles was further confirmed by X-ray diffraction (XRD) analysis. In the XRD patterns (Fig. 3a), the HEA nanoparticles typically exhibit two peaks at around $44^{\circ}$ and $51^{\circ}$, which can be assigned to the (111) and (200) planes of a fcc crystal, A small upshift of the peak position is discernible as the $\mathrm{Co} / \mathrm{Mo}$ ratio increases, but merely by $\sim 0.5^{\mathrm{O}}$ for the (111) peak from $\mathrm{C}_{15} \mathrm{Mo}_{55} \mathrm{Fe}_{10} \mathrm{Ni}_{10} \mathrm{Cu}_{10}$ to $\mathrm{C}_{55} \mathrm{Mo}_{15} \mathrm{Fe}_{10} \mathrm{Ni}_{10} \mathrm{Cu}_{10}$, indicating rather small differences in lattice strain among the HEA nanoparticles of various compositions. It is noticed that only two crystal phases are known for bimetallic $\mathrm{Co}-\mathrm{Mo}$ alloys, i.e., $\mathrm{Co}_{3} \mathrm{Mo}$ with a hexagonal structure
$\left(\mathrm{P}_{3} / m m c\right)$ and $\mathrm{Co}_{7} \mathrm{Mo}_{6}$ with a trigonal structure $(R-3 m)$. The XRD patterns recorded for the HEA- $\mathrm{Co}_{x} \mathrm{Mo}_{y}$ nanoparticles do not match either one of these two phases (Fig. 3a), but are more in line with those of the bimetallic alloys in $f c c$ phases albeit with shifted peak positions (Fig. 3a and Supplementary Fig. 8). This observation is consistent with the features of high-entropy alloys and confirms that the derived nanoparticles are in a single $f c c$ solid-solution phase ${ }^{17-19}$. The rather low peak intensities can be owing to the much smaller particle sizes than those previously reported HEAs ${ }^{20}$.

A combination of inductively coupled plasma-mass spectrometer (ICP-MS), X-ray photoemission spectroscopy (XPS) and energy dispersive X-ray spectroscopy (EDX) was employed to analyze the element compositions of the HEA nanoparticles. Among these three techniques, ICP (Table 1) and EDX provide composition information for the bulk of the nanoparticles, and average over the whole catalyst, whereas XPS is more sensitive to the surface region $(\sim 1 \mathrm{~nm}$ in depth estimated from the beam energy of $\mathrm{Al} \mathrm{K} \alpha$ ). The three methods generated quite consistent results for the alloy compositions (Fig. 3b), which is consistent with the homogeneous alloy nature as revealed by the STEMbased element mapping and excludes the occurrence of surface segregation or phase separation. The XPS analysis also shows that all the constituting elements of the HEA nanoparticles are in 

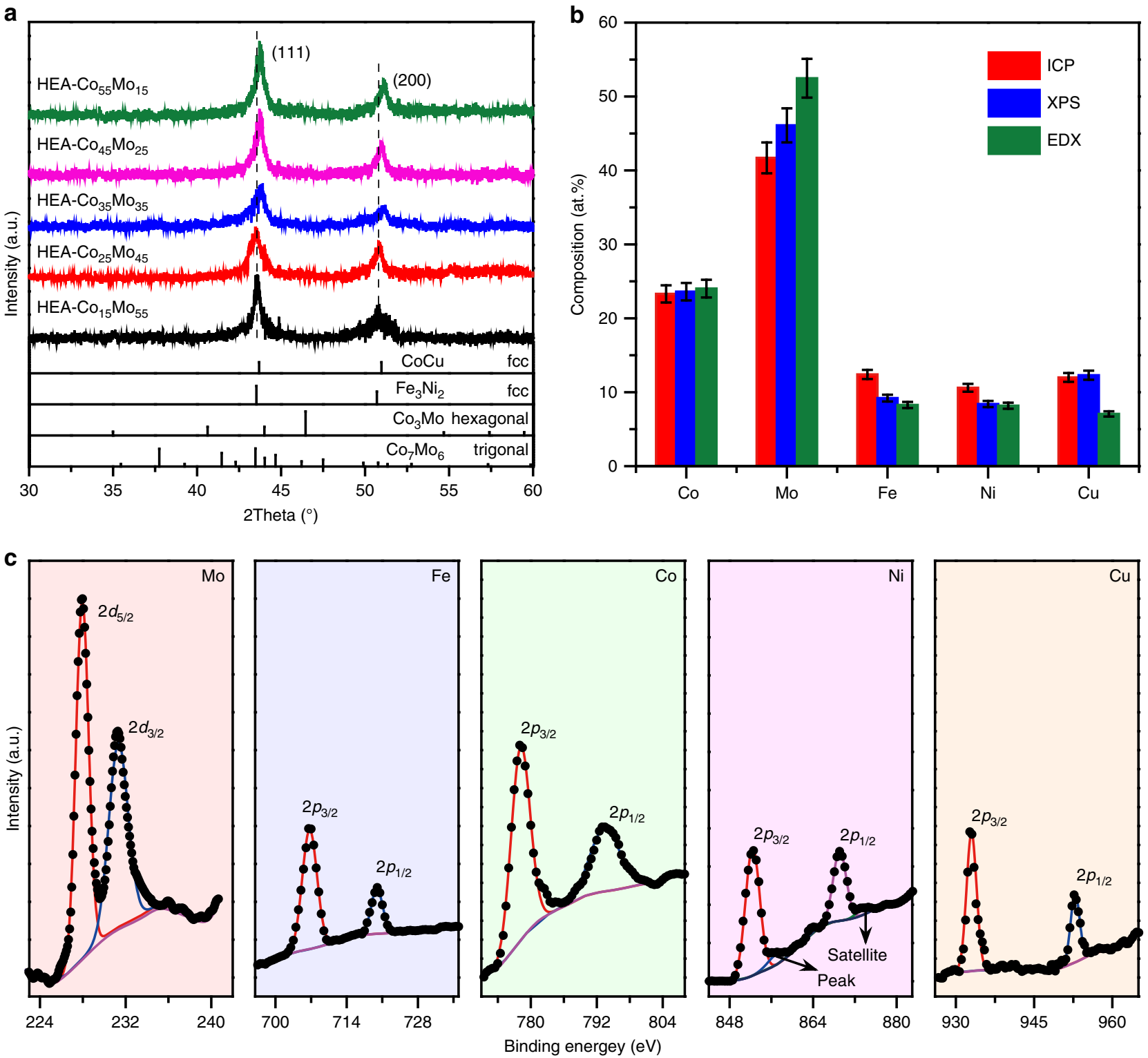

Fig. 3 Characterization of the HEA-Co $\mathrm{Mo}_{y}$ nanoparticles. a XRD patterns of the HEA nanoparticles supported on CNFs in comparison to the bimetallic standards of $\mathrm{CoCu}$ (PDF\# 50-1452), $\mathrm{Fe}_{3} \mathrm{Ni}_{2}$ alloy (PDF\# 65-5131), $\mathrm{Co}_{3} \mathrm{Mo}$ (JCDPS no. 29-0488), and $\mathrm{Co}_{7} \mathrm{Mo}_{6}$ (JCDPS no. 29-0489). b Comparison of the composition analyses for the HEA-C $\mathrm{Co}_{25} \mathrm{Mo}_{45}$ nanoparticles based on three different techniques: ICP-MS, XPS, and EDX, verifying the alloy homogeneity in the HEA nanoparticles. Error bars denote SDs. c XPS spectra collected at the Mo $3 d$, Fe $2 p$, Co $2 p$, Ni $2 p$, and $\mathrm{Cu}_{2 p}$ edges for the HEA-Co${ }_{25} \mathrm{Mo}_{45}$ nanoparticles

\section{Table 1 List of HEA-Cox $\mathrm{Mo}_{y}$ catalysts employed in this study}

\begin{tabular}{|c|c|c|c|c|c|c|c|}
\hline Samples & $\begin{array}{l}\text { Co } \\
\%\end{array}$ & $\begin{array}{l}\text { Mo } \\
\%\end{array}$ & $\begin{array}{l}\mathbf{F e} \\
\%\end{array}$ & $\begin{array}{l}\mathbf{N i} \\
\%\end{array}$ & $\begin{array}{l}\mathrm{Cu} \\
\%\end{array}$ & $\begin{array}{l}\text { Metal loadinga } \\
\text { wt. } \%\end{array}$ & $\begin{array}{l}S_{B E T} b \\
m^{2} / g\end{array}$ \\
\hline $\mathrm{HEA}-\mathrm{Co}_{15} \mathrm{Mo}_{55}$ & 14.3 & 51.8 & 12.6 & 11.2 & 10.1 & 8.2 & 150 \\
\hline $\mathrm{HEA}-\mathrm{Co}_{25} \mathrm{Mo}_{45}$ & 23.3 & 41.7 & 12.4 & 10.6 & 12.0 & 7.8 & 157 \\
\hline $\mathrm{HEA}-\mathrm{Co}_{45} \mathrm{Mo}_{25}$ & 42.9 & 23.5 & 11.7 & 11.5 & 10.4 & 8.8 & 148 \\
\hline $\mathrm{HEA}-\mathrm{Co}_{55} \mathrm{Mo}_{15}$ & 52.8 & 13.2 & 11.9 & 10.8 & 11.3 & 9.3 & 153 \\
\hline
\end{tabular}


a
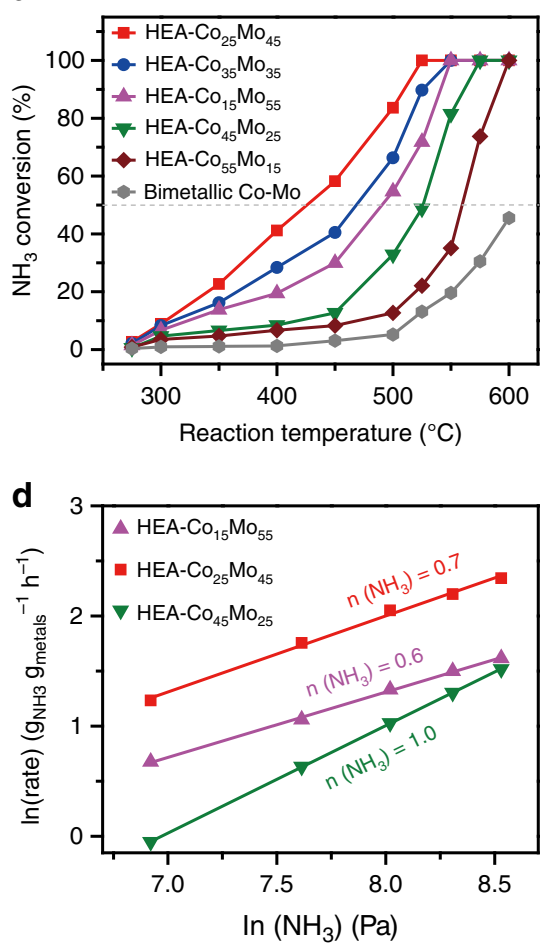

b
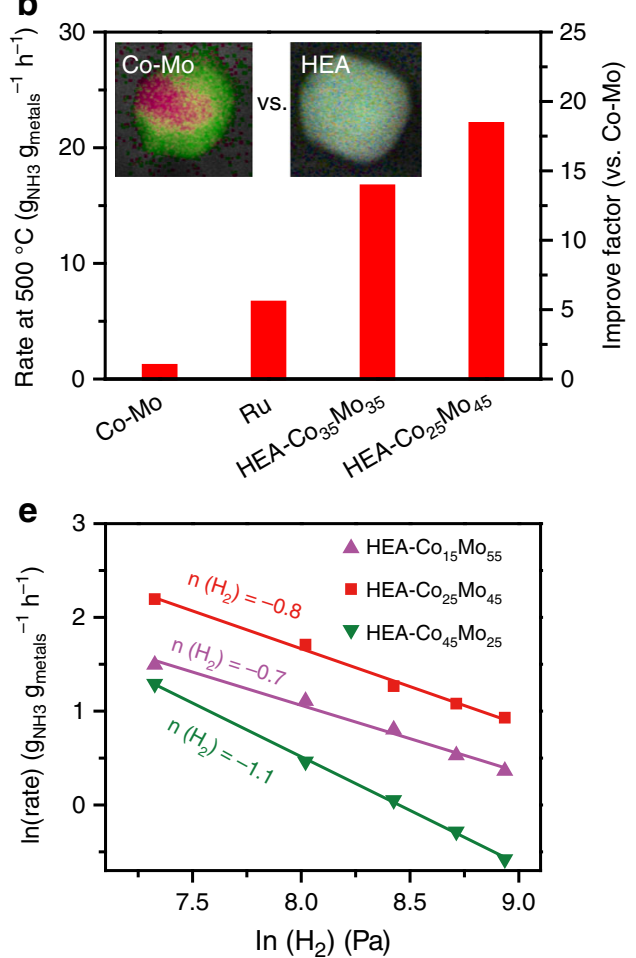

C

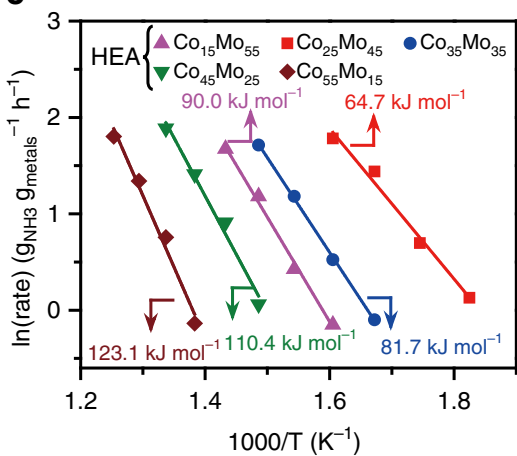

f

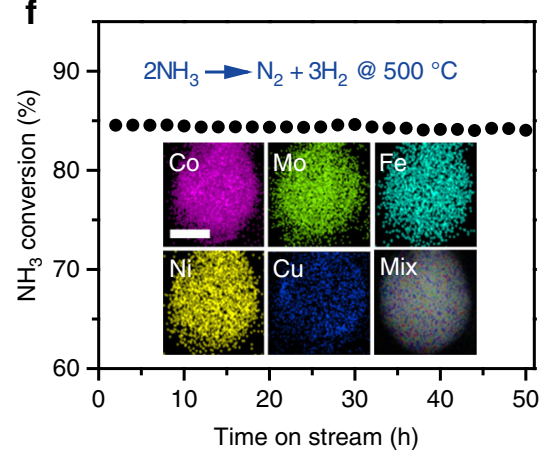

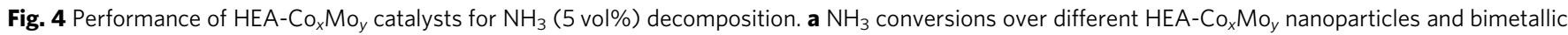
Co-Mo $(\mathrm{Co} / \mathrm{Mo}=25 / 45)$ depending on the reaction temperature (Space velocity $\left.=36 \mathrm{~L} \mathrm{~g}_{\text {cata }}{ }^{-1} \mathrm{~h}-{ }^{1}\right)$. $\mathbf{b}$ Comparison of reaction rates measured in the kinetic regime among bimetallic $\mathrm{Co}-\mathrm{Mo}, \mathrm{Ru}$, and $\mathrm{HEA}-\mathrm{Co}_{x} \mathrm{Mo}_{y}$ catalysts $\left(T=500{ }^{\circ} \mathrm{C}\right)$. Inset: element maps for the bimetallic $\mathrm{Co}-\mathrm{Mo}(\mathrm{Co} / \mathrm{Mo}=25 / 45)$ and $\mathrm{HEA}-\mathrm{CO}_{25} \mathrm{Mo}_{45}$ catalysts. c Arrhenius plots for $\mathrm{NH}_{3}$ decomposition on the HEA-Co $\mathrm{Mo}_{y}$ catalysts, showing different apparent activation energies


performed at $500{ }^{\circ} \mathrm{C}$ for the $\mathrm{HEA}-\mathrm{CO}_{25} \mathrm{Mo}_{45}$ catalyst. Inset: element map of the catalyst after the stability test; scale bar $=10 \mathrm{~nm}$

metallic states. Figure $3 \mathrm{c}$ presents representative XPS spectra recorded at the $3 d$ edge of Mo and $2 p$ edges of $\mathrm{Co}, \mathrm{Fe}, \mathrm{Ni}$, and $\mathrm{Cu}$ (see more spectra at the other edges in Supplementary Fig. 9). For example, the two peaks associated with the Mo $3 d_{5 / 2}$ and $3 d_{3 / 2}$ doublet are located at 228.0 and $231.2 \mathrm{eV}$, respectively, while the Co $2 p_{3 / 2}$ and $2 p_{1 / 2}$ peaks are at 778.2 and $793.3 \mathrm{eV}$, respectively. Both of these two sets of binding energies, as well as those for Fe, $\mathrm{Ni}$, and $\mathrm{Cu}$, are in line with the established values for pure metals $^{21}$. Charge transfer between the metals, or ligand effect ${ }^{22,23}$, thus may not be significant in the $\mathrm{HEA}-\mathrm{Co}_{x} \mathrm{Mo}_{y}$ nanoparticles.

Catalytic studies for ammonia decomposition. The HEA$\mathrm{Co}_{x} \mathrm{Mo}_{y}$ nanoparticles supported on carbon nanofibers were directly applied as catalysts for the ammonia decomposition reaction and compared to the bimetallic Co-Mo with the ratio of $25 / 45(\sim 20 \mathrm{~nm}$ in particle size, Supplementary Fig. 10, see the elemental maps of bimetallic Co-Mo with other ratios in Supplementary Fig. 11) and monometallic Ru ( 2-3 nm, Supplementary Fig. 12) catalysts with similar metal loadings and same substrates. The catalytic activity was systematically measured at $250-600^{\circ} \mathrm{C}$ using a plug flow reactor and $5 \mathrm{vol} \% \mathrm{NH}_{3}$ as the feeding gas. The bare CNF substrate was also measured and confirmed to be inactive for $\mathrm{NH}_{3}$ decomposition (Supplementary Fig. 13). Figure 4a summarizes the measured $\mathrm{NH}_{3}$ conversion as a function of temperature at a gas hourly space velocity (GHSV) of $36 \mathrm{Lg}_{\text {cat }}{ }^{-1} \mathrm{~h}^{-1}$. For all the HEA-Co $\mathrm{Mo}_{y}$ catalysts, the reaction has an onset temperature of $\sim 300^{\circ} \mathrm{C}$, and the $\mathrm{NH}_{3}$ conversion increases with the reaction temperature. Between 300 and $500^{\circ} \mathrm{C}$, the $\mathrm{NH}_{3}$ conversion follows the order HEA- $\mathrm{Co}_{25} \mathrm{Mo}_{45}>\mathrm{HEA}-$ $\mathrm{Co}_{35} \mathrm{Mo}_{35}>\mathrm{HEA}-\mathrm{Co}_{15} \mathrm{Mo}_{55}>\mathrm{HEA}-\mathrm{Co}_{45} \mathrm{Mo}_{25}>\mathrm{HEA}-\mathrm{Co}_{55} \mathrm{Mo}_{15}$, reaching $50 \%$ of conversion $\left(\mathrm{T}_{50}\right)$ at ca. $422,466,488,523$, and $558^{\circ} \mathrm{C}$, respectively. The reaction reaches saturation $(100 \%$ conversion) at $\sim 525^{\circ} \mathrm{C}$ on $\mathrm{HEA}-\mathrm{Co}_{25} \mathrm{Mo}_{45}$, as compared to $\sim 600{ }^{\circ} \mathrm{C}$ for $\mathrm{HEA}-\mathrm{Co}_{55} \mathrm{Mo}_{15}$. Most of the HEA catalysts are much more active than the bimetallic Co-Mo and monometallic $\mathrm{Ru}$, with the latter two giving $\mathrm{NH}_{3}$ conversions of only 46 and $73 \%$ at $600^{\circ} \mathrm{C}$ (Supplementary Fig. 14). Figure $4 \mathrm{~b}$ compares the reaction rate measured at $500{ }^{\circ} \mathrm{C}$ among the two most active HEA catalysts, bimetallic Co-Mo and monometallic Ru. The HEA$\mathrm{Co}_{35} \mathrm{Mo}_{35}$ and $-\mathrm{Co}_{25} \mathrm{Mo}_{45}$ catalysts reach a mass-specific rate of 16.7 and $22.1 \mathrm{~g}_{\mathrm{NH} 3} \mathrm{~g}_{\text {metals }}{ }^{-1} \mathrm{~h}^{-1}$ at $500^{\circ} \mathrm{C}$, representing improvement factors of $\sim 14$ and $\sim 19$ versus Co-Mo, respectively. Moreover, higher mass-specific activities were obtained with the HEA catalysts of reduced particle sizes (Supplementary Fig. 15). Compared to the precious metal $\mathrm{Ru}$, the $\mathrm{Co}_{25} \mathrm{Mo}_{45} \mathrm{Fe}_{10} \mathrm{Ni}_{10} \mathrm{Cu}_{10}$ catalyst achieves an improvement factor of $\sim 3$ versus $\mathrm{Ru}$. To take the different particle sizes into account, HEA- $\mathrm{Co}_{25} \mathrm{Mo}_{45}$ achieved an area-specific reaction rate of $0.74 \mathrm{~g}_{\mathrm{NH} 3} \mathrm{~m}^{-2} \mathrm{~h}^{-1}$, representing improvement factors of $\sim 24$ versus bimetallic Co-Mo and $\sim 19$ versus $\mathrm{Ru}$ (Supplementary Fig. 16). The superior performance of the HEA catalysts for $\mathrm{NH}_{3}$ decomposition is further revealed by a comprehensive comparison to the literature results with similar reaction conditions (Table 2 ).

Kinetic studies were also performed on the HEA catalysts with varying reaction temperature and gas composition. Figure $4 \mathrm{c}$ presents the Arrhenius plots of the reaction rate in dependence of temperature. The determined apparent activation energy $\left(E_{\text {app }}\right)$ varies with the $\mathrm{Co} / \mathrm{Mo}$ ratio, with the trend being consistent with that for the $\mathrm{NH}_{3}$ conversion, namely from the lowest $64.7 \mathrm{~kJ}$ $\mathrm{mol}^{-1}$ for the most active $\mathrm{HEA}-\mathrm{Co}_{25} \mathrm{Mo}_{45}$ to $123.1 \mathrm{~kJ} \mathrm{~mol}{ }^{-1}$ for the least active $\mathrm{HEA}-\mathrm{Co}_{55} \mathrm{Mo}_{15}$ catalyst. The activation energy measured here for $\mathrm{HEA}-\mathrm{Co}_{25} \mathrm{Mo}_{45}$ is comparable to those previously 
Table 2 Comparison of the catalytic performance for $\mathrm{NH}_{3}$ decomposition of different catalysts

\begin{tabular}{|c|c|c|c|c|c|c|c|}
\hline $\mathrm{Ru} / \mathrm{SiO}_{2}$ & 10 & 100 & 500 & 30,000 & 64 & 2283 & 2 \\
\hline $\mathrm{Ru} / \mathrm{CNTs}$ & 4.8 & 100 & 500 & 30,000 & 84 & 6241 & 5 \\
\hline $\mathrm{Ru} / \mathrm{TiO}_{2}$ & 4.8 & 100 & 500 & 30,000 & 64 & 11,096 & 27 \\
\hline $\mathrm{Ru} / \mathrm{MgO}$ & 5 & 100 & 500 & 30,000 & 41 & 8189 & 24 \\
\hline $\mathrm{CoMo} / \mathrm{SiO}_{2}$ & 5 & 100 & 500 & 36,000 & 14 & 1108 & 47 \\
\hline $\mathrm{FeMo} / \mathrm{La}-\mathrm{Al}_{2} \mathrm{O}_{3}$ & 10 & 100 & 500 & 46,000 & 8 & 1213 & 48 \\
\hline $\mathrm{Ni}_{2} \mathrm{Mo}_{3} \mathrm{~N}$ & 97 & 100 & 500 & 21,600 & 29 & 204 & 49 \\
\hline $\mathrm{Li}_{2} \mathrm{NH}-\mathrm{Fe}_{2} \mathrm{~N}$ & 81.2 & 100 & 500 & 60,000 & 38.1 & 1179 & 50 \\
\hline $\mathrm{Li}_{2} \mathrm{NH}-\mathrm{Mn}_{2} \mathrm{~N}$ & 81 & 100 & 500 & 60,000 & 59.1 & 2735 & 50 \\
\hline $\mathrm{HEA}-\mathrm{CO}_{25} \mathrm{Mo}_{45}$ & 7.8 & 5 & 500 & 36,000 & 84 & 1571 & This work \\
\hline $\mathrm{HEA}-\mathrm{CO}_{35} \mathrm{Mo}_{35}$ & 8.3 & 5 & 500 & 36,000 & 67 & 1128 & This work \\
\hline
\end{tabular}

reported for Ru-based catalysts $\left(57.8-83.7 \mathrm{~kJ} \mathrm{~mol}^{-1}\right)^{24-27}$. The determined reaction order of $\mathrm{NH}_{3}$ at $425^{\circ} \mathrm{C}$ increases with the $\mathrm{Co} / \mathrm{Mo}$ ratio, varying from 0.6 for HEA- $\mathrm{Co}_{15} \mathrm{Mo}_{55}$ to 1.0 for HEA$\mathrm{Co}_{45} \mathrm{Mo}_{25}$ (Fig. 4d). This indicates that the activation of $\mathrm{NH}_{3}$ is more difficult on the Co-rich catalysts. On the contrary, the $\mathrm{H}_{2}$ order (at $425^{\circ} \mathrm{C}$ ) decreases from -0.7 for HEA- $\mathrm{Co}_{15} \mathrm{Mo}_{55}$ to -1.1 for HEA-Co ${ }_{45} \mathrm{Mo}_{25}$, suggesting a less inhibition effect of $\mathrm{H}_{2}$ on the Mo-rich catalysts (Fig. 4e) ${ }^{28}$. The partial pressure of $\mathrm{N}_{2}$ was found to have little effect on the reaction rate (Supplementary Fig. 17), which is consistent with the previous conclusion drawn from Ru-based catalysts $^{29}$.

In addition to the enhanced catalytic activities, the HEA$\mathrm{Co}_{x} \mathrm{Mo}_{y}$ catalysts were further demonstrated to be highly stable under the reaction conditions for $\mathrm{NH}_{3}$ decomposition. Figure $4 \mathrm{f}$ presents the $\mathrm{NH}_{3}$ conversion recorded on $\mathrm{Co}_{25} \mathrm{Mo}_{45} \mathrm{Fe}_{10} \mathrm{Ni}_{10} \mathrm{Cu}_{10}$ over the course of continuous operation at $500^{\circ} \mathrm{C}$. The degradation in catalytic activity was negligible after $\sim 50 \mathrm{~h}$. The catalyst collected after this prolonged durability test was characterized by element mapping (see the insert in Fig. 4f) and XPS (Supplementary Fig. 18), with nearly no change found in alloy homogeneity or surface composition. A small amount $(\sim 1.4$ at.\%) of $N$ was detected on the used catalyst (Supplementary Fig. 19), but much less than what (e.g., $>10 \%$ for $\mathrm{Mo}_{3} \mathrm{Co}_{3} \mathrm{~N}$ ) one would expect for the formation of nitrides throughout the nanoparticles. It is likely that the bulk of the HEA nanoparticles were not subjected to nitridation during the $\mathrm{NH}_{3}$ decomposition reaction. The durable performance of the HEA catalysts is in line with the reported high thermal ${ }^{30}$ and chemical ${ }^{31,32}$ stabilities of HEAs.

Adsorption property and catalytic descriptor. The reaction mechanism of ammonia decomposition has been intensively investigated in both experimental and computational studies $1,6,8,25$. It is suggested that the recombinative desorption of nitrogen is the rate-determining step on $\mathrm{Fe}, \mathrm{Co}$, and $\mathrm{Ni}$, while the kinetics is limited by scission of the first N-H bond on Rh, Ir, Pd, $\mathrm{Pt}$, and $\mathrm{Cu}$ catalysts ${ }^{4}$, although some debates are still present in the literature 33,34 . Nevertheless, it is generally accepted that the binding strength of nitrogen is a good descriptor for ammonia decomposition catalysts, which largely determines both the stability of adsorbing intermediates (e.g., ${ }^{\star} \mathrm{N}$ and ${ }^{\star} \mathrm{NH}_{x}$ ) and activation energy of the rate-determining $\operatorname{step}^{6,10,12}$. In order to interpret the observed kinetic performance, we have performed temperature programmed desorption (TPD) of pre-adsorbed atomic nitrogen $\left(2^{\star} \mathrm{N} \rightarrow \mathrm{N}_{2}\right)$ to evaluate the adsorption properties of the HEA catalysts ${ }^{35-38}$.

Figure 5a shows the nitrogen TPD patterns recorded at a ramping rate of $10^{\circ} \mathrm{C} \mathrm{min}^{-1}$. Two distinct desorption peaks are consistently observed on all the $\mathrm{HEA}-\mathrm{Co}_{x} \mathrm{Mo}_{y}$ catalysts in the temperature range of $400-600^{\circ} \mathrm{C}$. These features resemble the previously reported results for $\mathrm{Ru}^{35,36}$ and $\mathrm{Fe}^{37,38}$ surfaces, and can be assigned to the recombinative desorption of nitrogen on ordered facets (such as (111) and (100) for the first peak) and undercoordinated sites (steps, edges, defects, etc. for the second peak), with the latter having stronger binding to nitrogen and thereby higher desorption temperatures due to the lower coordination numbers. A clear trend is established for the HEA catalysts of different compositions, with the desorption temperatures (both onset and peak positions) rising at decreasing $\mathrm{Co} / \mathrm{Mo}$ ratios, suggesting the continuous tuning of nitrogen binding strength by varying the HEA composition. According to the TPD theorem $^{39,40}$, we have conducted additional measurements at different ramping rates $\left(\beta=20\right.$ and $\left.30^{\circ} \mathrm{C} \mathrm{min}{ }^{-1}\right)$ to establish the plots of $\ln \left(\beta / T_{m}{ }^{2}\right)$ versus $1 / T_{m}$ ( $T_{m}$ is the peak position), in which the slopes are used to estimate the recombinative desorption energy of nitrogen $\left(\Delta E_{N}\right)$ (Fig. $5 b$ and Supplementary Fig. 20). Figure $5 c$ summarizes the derived values of $\Delta E_{\mathrm{N}}$ for the different HEA-Co $\mathrm{Mo}_{y}$ catalysts. As expected with the observations from the TPD patterns, the catalysts with higher $\mathrm{Co} / \mathrm{Mo}$ ratios have lower $\Delta E_{\mathrm{N}}$, ranging from $\sim 121-125 \mathrm{~kJ} \mathrm{~mol}^{-1}$ for $\mathrm{HEA}-\mathrm{Co}_{15} \mathrm{Mo}_{55}$ to $\sim 42-44 \mathrm{~kJ} \mathrm{~mol}^{-1}$ for HEA-Co ${ }_{55} \mathrm{Mo}_{15}$. It is noticed that the most active $\mathrm{HEA}-\mathrm{Co}_{25} \mathrm{Mo}_{45}$ catalyst has a $\Delta E_{\mathrm{N}}$ value of $\sim 79 \mathrm{~kJ} / \mathrm{mol}$, which is very close to the $\Delta E_{\mathrm{N}}\left(84 \mathrm{~kJ} \mathrm{~mol}^{-1}\right)^{24}$ of $\mathrm{Ru}$, explaining the high and comparable catalytic activities of the HEA-Co $\mathrm{Mo}_{y}$ to $\mathrm{Ru}$-based catalysts. $\mathrm{HEA}-\mathrm{Co}_{35} \mathrm{Mo}_{35}$ has the same $\mathrm{Co} / \mathrm{Mo}$ ratio as $\mathrm{Co}_{3} \mathrm{Mo}_{3} \mathrm{~N}$ but binds to nitrogen much less strongly (Fig. $5 \mathrm{c}$ ). This difference $\left(\sim 65 \mathrm{~kJ} \mathrm{~mol}^{-1}\right)$ can be ascribed to the presence of other weakly binding metals $(\mathrm{Fe}, \mathrm{Ni}$, and $\mathrm{Cu})$ in and on the surface of the HEA catalysts.

With the estimated nitrogen adsorption energies, we are able to interpret the correlation between composition and catalytic performance of the HEA- $\mathrm{Co}_{x} \mathrm{Mo}_{y}$ catalysts. Figure $5 \mathrm{~d}$, e present the plots of $\mathrm{NH}_{3}$ decomposition rate (at $500^{\circ} \mathrm{C}$ ) and activation energy versus $\Delta E_{\mathrm{N}}$. Both plots exhibit a volcano-type behavior with $\mathrm{HEA}-\mathrm{Co}_{25} \mathrm{Mo}_{45}$ being close to the peak position. According to the Sabatier principle, we can infer that, on the left side of this 

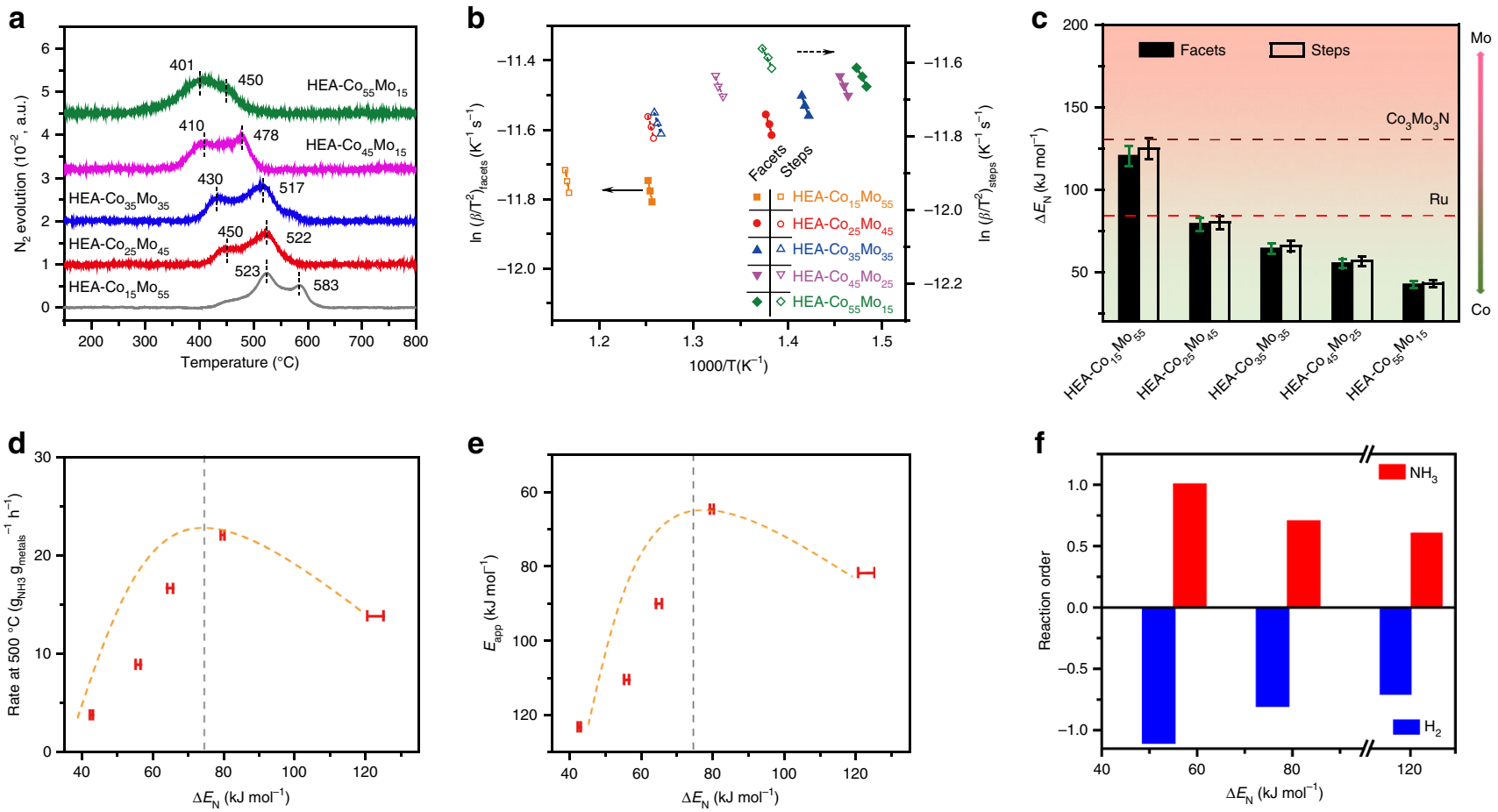

Fig. 5 Surface adsorption properties of $\mathrm{HEA}-\mathrm{Co}_{x} \mathrm{Mo}_{y}$. a Nitrogen TPD profiles recorded with a temperature ramping rate of $10^{\circ} \mathrm{C}$ min ${ }^{-1}$. $\mathbf{b}, \mathbf{c}$ Estimation of the nitrogen adsorption energies $\left(\Delta E_{N}\right)$ for the HEA-Co $\mathrm{Mo}_{y}$ catalysts by using the plots of $\operatorname{Ln}\left(\beta / T^{2}\right) \sim 1 / T$ for the nitrogen TPD profiles $(\beta=10,20$, and $30{ }^{\circ} \mathrm{C} \mathrm{min}^{-1}$ represents the ramping rates used for the TPD measurements). d, e Correlations between $\Delta E_{N}$ and catalytic activities (d) and $E_{a p p}(\mathbf{e})$ showing a volcano-type behavior for the $\mathrm{HEA}-\mathrm{Co}_{x} \mathrm{Mo}_{y}$ catalysts, with $\mathrm{HEA}-\mathrm{Co}_{25} \mathrm{Mo}_{45}$ being close to the peak position. $\mathbf{f}$ Plots of the $\mathrm{NH}_{3}$ and $\mathrm{H}_{2}$ reaction orders (at $425^{\circ} \mathrm{C}$ ) versus the nitrogen adsorption energies. Error bars denote SDs

peak, the catalysts (more Co-rich) bind to $\mathrm{N}$ too weakly and thus gives rise to rather higher kinetic barriers for dehydrogenation $\left(\mathrm{NH}_{3} \rightarrow{ }^{\star} \mathrm{NH}_{2} \rightarrow{ }^{*} \mathrm{NH} \rightarrow{ }^{\star} \mathrm{N}\right.$ ), whereas on the right side (more Mo-rich) the binding is too strong for $\mathrm{N}$ to recombine and desorb from the surface $\left(2^{*} \mathrm{~N} \rightarrow \mathrm{N}_{2}\right)$, and a tradeoff between these two factors gives rise to an optimal, intermediate binding energy for the reaction (Fig. 6). The finding here can be further correlated to the dependence of reaction orders on $\Delta E_{\mathrm{N}}$. As shown in Fig. 5f, the catalysts with weaker $\mathrm{N}$ binding energy has higher $\mathrm{NH}_{3}$ order, suggesting that the kinetics of $\mathrm{NH}_{3}$ decomposition is more limited by $\mathrm{NH}_{3}$ activation, or probably dehydrogenation of the first N-H bond, on the HEA catalysts of higher Co contents. Since the binding strengths of nitrogenous species $\left({ }^{*} \mathrm{NH}_{x}, x=0,1,2\right.$, and 3) likely scale linearly with each other ${ }^{41-43}$, we can expect that the ${ }^{\star} \mathrm{NH}_{x}$ species bind less strongly on the more Co-rich HEA catalysts, which is also in line with the stronger hydrogen inhibition effect found for these catalysts (Fig. 5f).

From the above discussion, we can attribute the high catalytic activity of $\mathrm{NH}_{3}$ decomposition achieved with the HEA catalysts to the robust tuning of surface adsorption properties, as enabled by the continuous varying of alloy composition (Co/Mo ratio). Noticeably, the optimal value of $\Delta E_{\mathrm{N}} \sim 79 \mathrm{~kJ} \mathrm{~mol}^{-1}$ identified here is consistent with the value $\left(\sim 74 \mathrm{~kJ} \mathrm{~mol}^{-1}\right)$ predicted from density functional theory calculations for the given reaction condition, i.e., $5 \mathrm{vol} \%$ of $\mathrm{NH}_{3}{ }^{12}$. We also notice that, for the optimal design of practical reactors, it is desirable to have cascaded catalyst layers with gradually changing nitrogen binding strengths, so that the surface property can be optimized to match the varying concentration of $\mathrm{NH}_{3}$ along the flow ${ }^{44}$. We show here that the HEA catalysts can be readily tailored to achieve such a design by simply varying the $\mathrm{Co} / \mathrm{Mo}$ ratios. For example, HEA$\mathrm{Co}_{55} \mathrm{Mo}_{15}$ have been identified to be the best-performing catalyst for the decomposition of pure $\mathrm{NH}_{3}$, which gives rise to catalytic activity improvement factors of $\sim 118$ versus bimetallic Co-Mo and $\sim 40$ versus $\mathrm{Ru}$ (Fig. 7 and Supplementary Fig. 21). The even more substantial catalytic enhancements found here (than the results presented above for $5 \mathrm{vol} \%$ of $\mathrm{NH}_{3}$ ) can be well understood in such a way: the $\Delta E_{\mathrm{N}}$ value of $\mathrm{HEA}-\mathrm{Co}_{55} \mathrm{Mo}_{15}$ $\left(\sim 42 \mathrm{~kJ} \mathrm{~mol}^{-1}\right.$, according to Fig. $\left.5 \mathrm{c}\right)$ is very close to the optimal $\left(\sim 39 \mathrm{~kJ} \mathrm{~mol}^{-1}\right)$ predicted for the reaction at $100 \mathrm{vol} \%$ of $\mathrm{NH}_{3}{ }^{12}$, whereas the values of previous $\mathrm{Co}_{3} \mathrm{Mo}_{3} \mathrm{~N}$ and $\mathrm{Ru}$ catalysts are quite away from this optimal point.

Atomistic modeling of HEA nanoparticles. The correlations among composition, adsorption property and catalytic performance discussed above point to a scaling relationship between $\Delta E_{\mathrm{N}}$ and the elemental ratio of Co/Mo (Fig. $5 \mathrm{c}$ ), which governs the catalytic activity of the HEA catalysts. This relationship can be ascribed to the presence of well mixed Co-Mo sites on the surface with the ratio being consistent with the bulk compositions (Fig. 3b). We have used atomistic models to elucidate this surface site mixing mechanism in the HEA catalysts.

HEA- $\mathrm{Co}_{25} \mathrm{Mo}_{45}\left(\mathrm{Co}_{25} \mathrm{M}_{45} \mathrm{Fe}_{10} \mathrm{Ni}_{10} \mathrm{Cu}_{10}\right)$ was chosen as the example and modeled in a cuboctahedral shape with FCC lattice. From the survey of those bulk multi-component alloys to form solid-solution HEAs, it has been found that the formation of HEA most often requires: the parameter gauging the atomic size difference $\delta \leq 6.6 \%$ and the enthalpy of formation $-11.6<\Delta H_{\text {mix }}<3.2\left(\mathrm{kJmol}^{-1}\right)^{45,46}$. In this work, we have calculated that $\mathrm{HEA}-\mathrm{Co}_{25} \mathrm{Mo}_{45}$ has $\delta=5.4 \%, \Delta H_{\text {mix }}=$ $0.65\left(\mathrm{kJmol}^{-1}\right)$, and $\Delta S_{\text {mix }}=11.6\left(\mathrm{~J}(\mathrm{Kmol})^{-1}\right)$. Hence, we predict that HEA-Co $\mathrm{Co}_{25} \mathrm{Mo}_{45}$ is likely to form solid-solution HEAs under the ammonia decomposition reaction conditions. The five elements are initially randomly assigned to each lattice site according to the nominal composition. To investigate the phase 


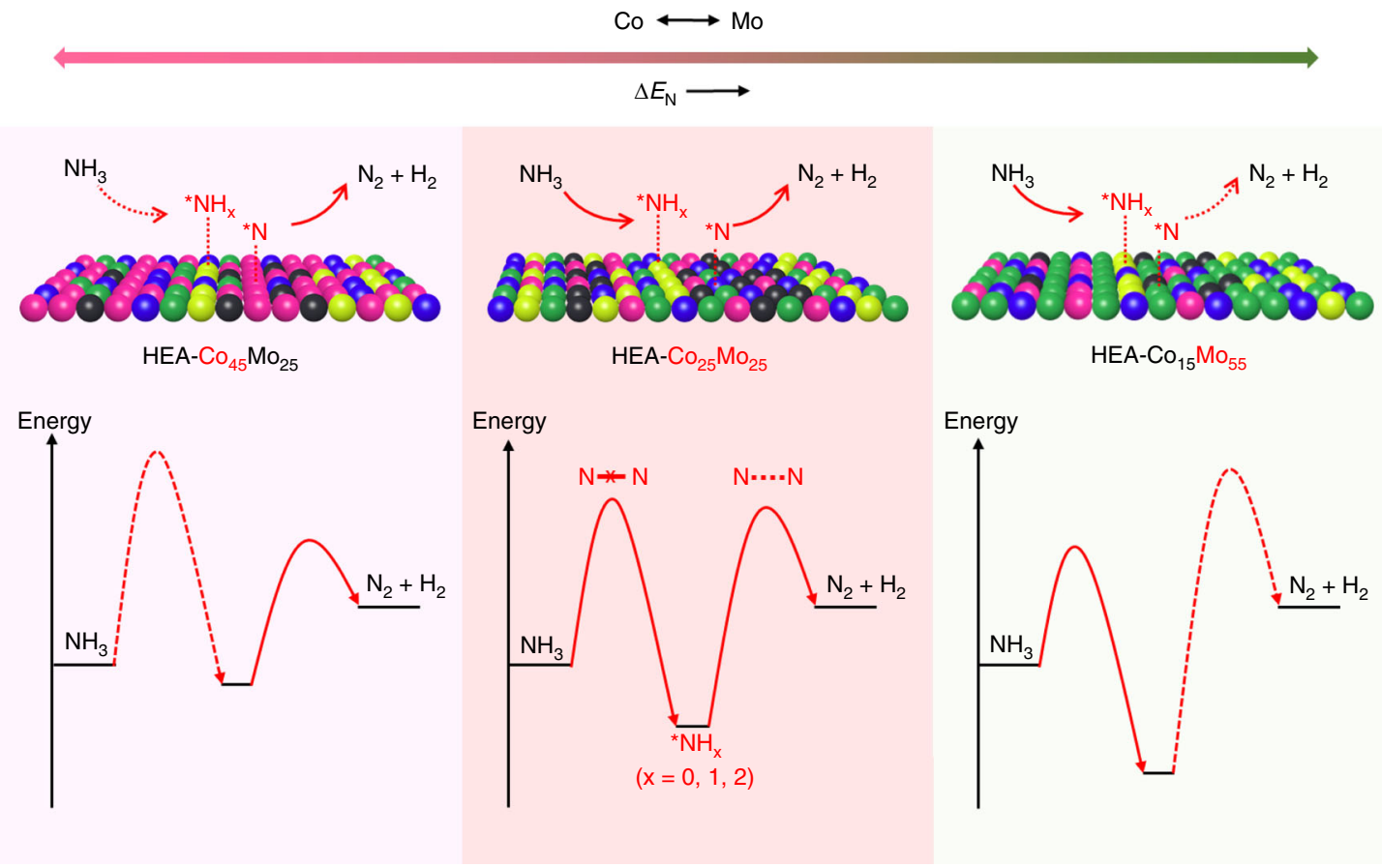

Fig. 6 Schematic illustration of the rate-limiting factors in $\mathrm{NH}_{3}$ decomposition. The rate-limiting factors are labeled with dash lines in the lower panel. On Co-rich surface (left), the rate is limited by activation or dehydrogenation of $\mathrm{NH}_{3}$; on Mo-rich surface, the rate is limited by the recombinative desorption of ${ }^{\star} \mathrm{N}$; Balance for these two steps is reached on an intermediate composition ( $\mathrm{HEA}-\mathrm{CO}_{25} \mathrm{Mo}_{45}$ )



Fig. $7 \mathrm{NH}_{3}$ decomposition at different concentrations. The composition of $\mathrm{HEA}-\mathrm{Co}_{x} \mathrm{Mo}_{y}$ catalysts were robustly tuned to optimize the surface properties for different reaction conditions (e.g., 5 vs. 100 vol\% $\mathrm{NH}_{3}$ )

stability of the HEA nanoparticles, Monte Carlo (MC) simulations are performed at three different temperatures (i.e., 573, 750, and $1000 \mathrm{~K})$. The atomic structures after 10 million MC steps are shown in Fig. 8a-c. All the resulting structures show random distribution of the five elements, and no apparent chemical ordering such as the segregation of single elements or formation of intermetallic phases was observed, confirming the formation of HEA under the given conditions. This finding is further corroborated by statistical analysis of the averaged composition of the nearest-neighbor lattice sites (with a cutoff radius of $3.0 \AA$ ) for a given element (Fig. 8d-i). For an ideal solid solution, this averaged composition should be equal to the nominal composition of the HEA nanoparticle, which are represented by the dash lines in Fig. 8d-i. Our results show that the nearest-neighbor (NN) compositions averaged over all the atoms only deviate slightly from the nominal composition throughout the three temperatures investigated, implying the absence of long-range chemical ordering. On the other hand, some degree of shortrange ordering is predicted in the modeled nanoparticle: $\mathrm{Fe}, \mathrm{Co}$, and $\mathrm{Ni}$ atoms exhibit a relatively higher affinity around Mo atom, whereas there is a moderate repulsive interaction between $\mathrm{Cu}$ $\mathrm{Mo}, \mathrm{Fe}-\mathrm{Co}, \mathrm{Co}-\mathrm{Ni}$, and $\mathrm{Co}-\mathrm{Cu}$ atom pairs. This short-range ordering is even prominent for surface atoms, as shown in Fig. $8 \mathrm{~g}-\mathrm{i}$. Overall, our atomistic modeling reveals that the HEA$\mathrm{Co}_{x} \mathrm{Mo}_{y}$ nanoparticles have a single solid solution phase with only slight short-range chemical ordering throughout the investigated temperature range. It also confirms the presence of well mixed surface sites on the HEA catalysts and suggests that the experimentally observed scaling relationship between the nanoparticle composition and the surface adsorption property can be understood via the surface site mixing mechanism ${ }^{9,10}$. It should be noted that our atomistic modeling results are consistent with the prediction based on simple thermodynamic calculations, confirming the tendency of the given quinary composition to form a single solid-solution phase. More importantly, the structural similarity at the different temperatures (from 573 to $1000 \mathrm{~K}$ ) underlines the high thermal stability of the HEA nanoparticles, consistent with the observation from the catalytic durability studies (see Table 2$)^{47-51}$.

\section{Discussion}

We have developed advanced ammonia decomposition catalysts based on high-entropy alloys made of earth-abundant elements. The HEA CoMoFeNiCu nanoparticles enabled robust tuning of the $\mathrm{Co} / \mathrm{Mo}$ ratio and breaking the miscibility limitation in conventional bimetallic Co-Mo catalysts. These novel catalysts achieved significantly enhanced catalytic activities and stabilities, 
a
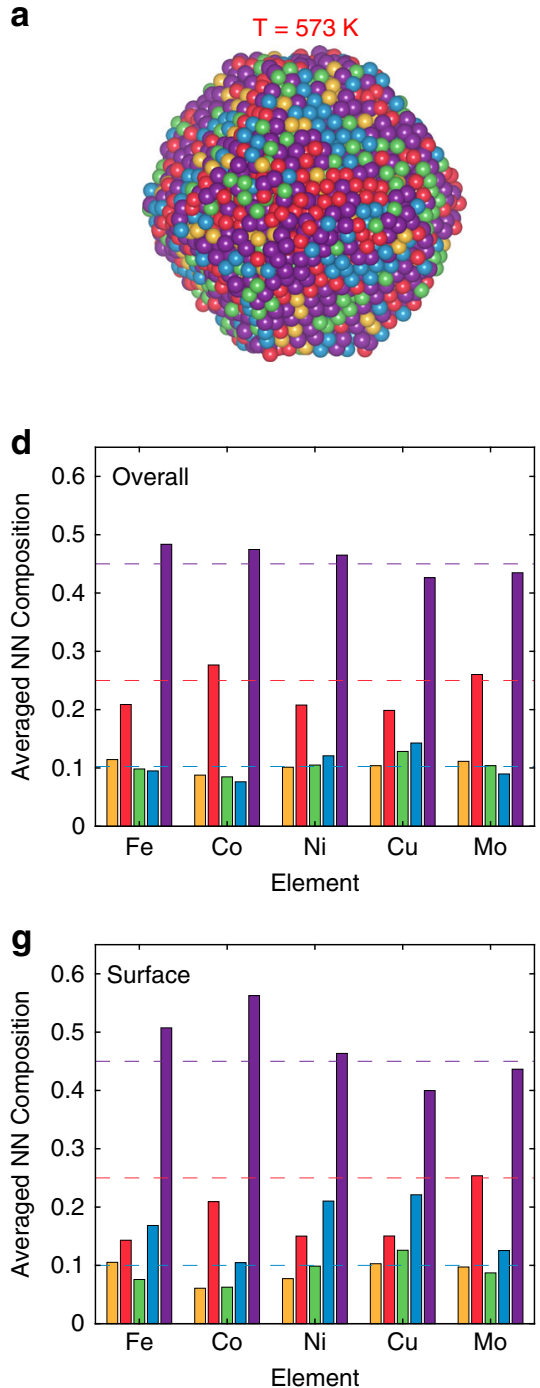

b



e
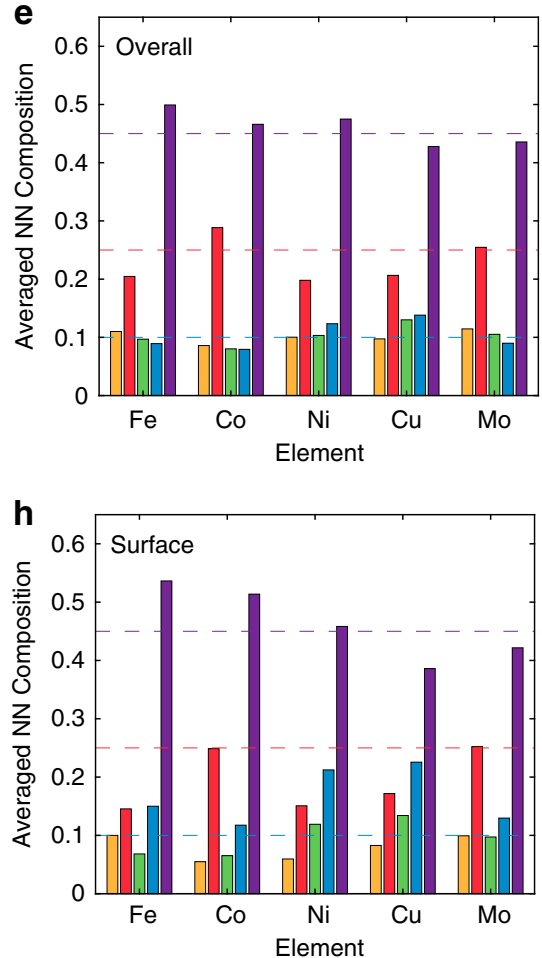

C

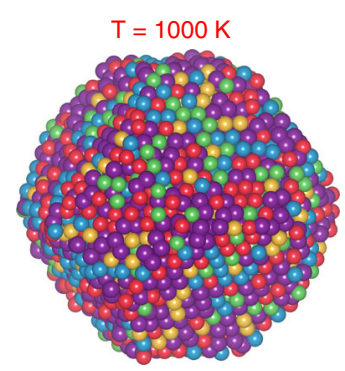

f



i



Fig. 8 Atomic structure of HEA catalysts. Atomistic model of HEA- $\mathrm{CO}_{25} \mathrm{Mo}_{45}$ nanoparticle predicted by using $\mathrm{MC}$ simulations at different temperatures: a $573 \mathrm{~K}$; b $750 \mathrm{~K}$; and c $1000 \mathrm{~K}$. The composition of the first-nearest neighbor lattice sites around a specific element type averaged over (d-f) all atoms and (g-i) surface atoms in the corresponding nanoparticle. The dashed lines represent the nominal composition of the nanoparticle $\left(\mathrm{Co}_{0.25} \mathrm{Mo}_{0.45} \mathrm{Fe}_{0.1} \mathrm{Ni}_{0.1} \mathrm{Cu}_{0.1}\right)$

with the improvement factors exceeding 20 times as compared to precious metal $\mathrm{Ru}$, and even more so versus conventional Co-Mo catalysts. Their catalytic activities and kinetics were further found to exhibit a volcano-type behavior independent of the $\mathrm{Co} / \mathrm{Mo}$ ratio, which was successfully interpreted by using the nitrogen adsorption energy as the descriptor and a mixed surface site mechanism derived from atomistic modeling. The robust tunability of alloy composition and surface adsorption property demonstrated on the HEA catalysts indicate great potential for their implementation in practical reactors with the catalytic performance optimized under various reaction conditions.

\section{Methods}

Synthesis. $8 \mathrm{wt} \%$ polyacrylonitrile (PAN, Sigma Aldrich) in dimethylformamide (DMF, Sigma Aldrich) was used to make a polymer nanofiber network via electrospinning (voltage: $15 \mathrm{kV}$, distance: $10 \mathrm{~cm}$, feed rate: $0.065 \mathrm{ml} \mathrm{min}^{-1}$, collected on a rotating drum at $40 \mathrm{rpm}$ ). The derived nanofibers were stabilized in air at $533 \mathrm{~K}$ for $6 \mathrm{~h}$ and then carbonized at $1173 \mathrm{~K}$ for 2 hours in argon using a tube furnace. The CNF films can be further thermally activated at $1023 \mathrm{~K}$ for $2 \mathrm{~h}$ in $\mathrm{CO}_{2}$ atmosphere to create surface defects for effective particle dispersion.

Typically, the individual metal salts (chloride salts, $\mathrm{FeCl}_{3}, \mathrm{CoCl}_{2}, \mathrm{NiCl}_{2}, \mathrm{CuCl}_{2}$, and $\mathrm{MoCl}_{3}$ from Sigma Aldrich) were dissolved in ethanol with five designed ratios of $\mathrm{Co}_{x} \mathrm{Mo}_{y} \mathrm{Fe}_{10} \mathrm{Ni}_{10} \mathrm{Cu}_{10}(x+y=70$, and the atomic ratio of $\mathrm{Co} / \mathrm{Mo}$ was controlled to be $15 / 55,25 / 45,35 / 35,45 / 25$, and 55/15). The CNF films were suspended over the trench of two glass slides $(2 \mathrm{~cm}$ gap) and then connected to two copper electrodes by silver paste for subsequent precursor solution loading. Then the salt precursor solution was dipped onto the CNF film with a precursor loading of $5 \mu \mathrm{mol} \mathrm{cm}{ }^{-2}$. The samples were left to dry at room temperature.

The carbothermal shock process was performed through Joule heating of the precursor-loaded CNF films in an argon-filled glovebox. A Keithley SourceMeter (2425) was used as the electrical power source and the sweep function from Keithley was used to provide the thermal shock, in which the current (temperature), duration (thermal shock time), and cooling speed (ramp rate) of the electrical pulse can be adjusted. We chose a 55-ms electrical pulse to synthesize the high-entropy alloy nanoparticles.

We used a time-resolved pyrometer to measure the emitted light intensity from the sample and estimate the temperature during the thermal shock process. The emitted light was dispersed at a resolution of $6.5 \mathrm{~nm} \mathrm{~mm}^{-1}$ and then collected by a 32-channel photomultiplier tube array. The full spectrum can be integrated from the 32-channels and then fitted to the blackbody radiation equation to estimate the temperature.

The control sample, bimetallic Co-Mo supported on $\mathrm{CNFs}(\mathrm{Co} / \mathrm{Mo}=15 / 55,25$ / $45,35 / 35,45 / 25$, and $55 / 15$ ), were prepared by the same method as HEA nanoparticles did. Typically, $\mathrm{CoCl}_{2}$ and $\mathrm{MoCl}_{3}$ were dissolved in ethanol with the atomic ratio of Co/Mo was 25/45 and total loading of $10 \mathrm{wt} \%$. Then the salt precursor solution was dipped onto the CNF film with a precursor loading of $5 \mu \mathrm{mol} \mathrm{cm}{ }^{-2}$. The samples were left to dry at room temperature, and then underwent the carbothermal shock process described as above.

Another control sample, $\mathrm{Ru} / \mathrm{CNF}$ was prepared by incipient wetness impregnation. Basically, $50 \mathrm{mg}$ carbon nanofibers were dispersed in ethanol, and sonicated for $1 \mathrm{~h}$. Certain amount of $\mathrm{RuCl}_{3} \cdot \mathrm{xH}_{2} \mathrm{O}$ was dissolved in ethanol 
(Nominal Ru loading is $10 \mathrm{wt} \%$ ). Then these solutions were mixed together and sonicated for another $30 \mathrm{~min}$. After that, the solvent was removed by using a rotary evaporator. The obtained solid was dried in vacuum and then calcined at $700{ }^{\circ} \mathrm{C}$ in argon for $2 \mathrm{~h}$.

Characterization. X-ray diffraction (XRD) patterns were collected on a PANalytical X'Pert ${ }^{3} \mathrm{X}$-ray diffractometer equipped with a $\mathrm{Cu} \mathrm{K} \alpha$ radiation source $(\lambda=$ $1.5406 \AA$ ). Nitrogen adsorption measurements were performed using a Micromeritics ASAP 2010 system with the samples degassed under vacuum at $300^{\circ} \mathrm{C}$ for $5 \mathrm{~h}$. Specific surface area (SSA) was calculated using the Brunauer-Emmett-Teller (BET) theory. Inductively coupled plasma-mass spectroscopy (ICP-MS) analysis was carried out using a PerkinElmer Elan DRC II Quadrupole system, for which the solutions were prepared by digesting the catalysts in aqua regia followed by dilution with $2 \%$ hydrochloric acid $(\mathrm{HCl})$.

The microstructure and morphology of the HEA catalysts were characterized by using scanning electron microscopy (SEM, Hitachi SU-70 FEG-SEM at $10 \mathrm{kV}$ ) and transmission electron microscopy (TEM, JEOL 2100 F FEG TEM/STEM operated at $200 \mathrm{kV}$ ) imaging. High-angle annular dark-field (HAADF) STEM images and STEM-EDS mapping were acquired using a JEOL TEM/STEM ARM 200CF (equipped with an Oxford X-max 100TLE windowless X-ray detector) at a 22-mrad probe convergence angle and a 90-mrad inner-detector angle.

$\mathrm{X}$-ray photoelectron spectroscopy (XPS) analysis was performed on a Thermo Fisher Scientific Escalab 250Xi spectrometer with $\mathrm{Al} \mathrm{K} \alpha$ radiation as the excitation source. Before measurements, the $\mathrm{Co}_{\mathrm{x}} \mathrm{Mo}_{\mathrm{y}}$-HEA catalysts were reduced in $\mathrm{H}_{2}$ at $600^{\circ} \mathrm{C}$ for $2 \mathrm{~h}$. The adventitious carbonaceous $\mathrm{C} 1 \mathrm{~s}$ line $(284.6 \mathrm{eV})$ was used to calibrate the binding energy (BE). The XPS spectra were deconvoluted using Gaussian-Lorentzian functions after the Shirley background subtraction, with the integrated peak areas being used to estimate the surface chemical compositions.

The nitrogen TPD experiments were carried out on a Micromeritics AutoChem II chemisorption analyzer equipped with an Omnistar MS detector. Typically, 30 mg of $\mathrm{Co}_{\mathrm{x}} \mathrm{Mo}_{\mathrm{y}}$-HEA catalysts were loaded in a U-type sample tube, reduced in $\mathrm{H}_{2}$ $\left(30 \mathrm{~mL} \mathrm{~min}^{-1}\right)$ at $600^{\circ} \mathrm{C}$ for $2 \mathrm{~h}$, and then blown with $\mathrm{He}\left(30 \mathrm{~mL} \mathrm{~min}^{-1}\right)$ for $1 \mathrm{~h}$ to remove the hydrogen adsorbed on the catalyst surface. After this, the flowing gas was switched to $\mathrm{N}_{2}\left(30 \mathrm{~mL} \mathrm{~min}^{-1}\right)$ and kept at $600^{\circ} \mathrm{C}$ for $90 \mathrm{~min}$, then cooled down to $100^{\circ} \mathrm{C}$ under $\mathrm{N}_{2}$ atmosphere. At $100^{\circ} \mathrm{C}, \mathrm{N}_{2}$ was switched to $\mathrm{He}$ for removing the residual nitrogen on the catalyst surface. Finally, TPD measurement was conducted under $\mathrm{He}$ atmosphere at a ramping rate of $10^{\circ} \mathrm{C} \mathrm{min}^{-1}$ and up to $800{ }^{\circ} \mathrm{C}$. Over this process, mass spectrum signals of $\mathrm{He}(4 \mathrm{amu})$ and $\mathrm{N}_{2}(28 \mathrm{amu})$ were monitored. For measuring combinative $\mathrm{N}_{2}$ desorption energy, three different ramping rates $\left(10,20,30^{\circ} \mathrm{C} \mathrm{min}^{-1}\right)$ were used in a similar process.

Catalytic studies. Catalytic decomposition of $\mathrm{NH}_{3}$ was conducted in a fixed-bed flow reactor at atmospheric pressure. Typically, $25 \mathrm{mg}$ of catalyst was loaded into a quartz tube reactor $\left(7 \mathrm{~mm}\right.$ i.d.). The catalyst was heated to $600^{\circ} \mathrm{C}$ at a rate of $5^{\circ} \mathrm{C}$ $\mathrm{min}^{-1}$ under $\mathrm{H}_{2}\left(50 \mathrm{~mL} \mathrm{~min}^{-1}\right)$ for $2 \mathrm{~h}$ and then purged by Helium $\left(50 \mathrm{~mL} \mathrm{~min}^{-1}\right)$ for $1 \mathrm{~h}$. After this, the catalyst was cooled down to $275^{\circ} \mathrm{C}$ under $\mathrm{He}$ atmosphere. At $275^{\circ} \mathrm{C}$, the gas flow was switched to 5 or $100 \mathrm{vol} \% \mathrm{NH}_{3}$ (balanced by He). The gas hourly space velocity (GHSV) was adjusted to $36 \mathrm{~L} \mathrm{~g}_{\text {cat }}{ }^{-1} \mathrm{~h}^{-1}$ by controlling the flow rate. The reaction was then carried out at various temperatures, which was increased stepwise from 275 to $600^{\circ} \mathrm{C}$, and steady state was allowed to reach before the product analysis. To determine the conversions of reactant, a FTIR spectrometer (Nicolet 6700, Thermo Scientific) equipped with a long path $(5 \mathrm{~m})$ gas cell and a MCT detector (with a resolution of $8 \mathrm{~cm}^{-1}$ ) was used to analyze $\mathrm{NH}_{3}$ $\left(964 \mathrm{~cm}^{-1}, 929 \mathrm{~cm}^{-1}\right)$. The $\mathrm{NH}_{3}$ conversion were calculated using $\mathrm{NH}_{3}$ conversion $=\frac{\left[\mathrm{NH}_{3}\right]_{\text {inlet }}-\left[\mathrm{NH}_{3}\right]_{\text {outlet }}}{\left(1+\left[\mathrm{NH}_{3}\right]_{\text {outlet }}\right) \times\left[\mathrm{NH}_{3}\right]_{\text {inlet }}} \times 100 \%$, where $\left[\mathrm{NH}_{3}\right]_{\text {inlet }}$ and $\left[\mathrm{NH}_{3}\right]_{\text {outlet }}$ refer to the measured concentrations of $\mathrm{NH}_{3}$ fed into and flowing out of the reactor. $\mathrm{N}_{2}$ and $\mathrm{H}_{2}$ were detected by using a GC-BID equipped with Poropak $\mathrm{Q}$ packed column with Helium as the carrier gas.

The measurements of reaction rates and kinetics were carried out at reduced catalyst loadings and the GHSV was adjusted to $100 \mathrm{~L} \mathrm{~g}_{\mathrm{cat}}{ }^{-1} \mathrm{~h}^{-1}$, ensuring that the reaction condition was within the kinetic zone ( $<15 \%$ conversion) and mass transfer was not limited. The reaction orders were measured at $425^{\circ} \mathrm{C}$. The TOFs (turnover frequencies) were calculated based on the surface metal atoms. The surface metal atoms of bimetallic Co-Mo and HEA-Co $\mathrm{Mo}_{\mathrm{y}}$ catalysts were estimated by assuming the nanoparticles as perfect FCC cubo-octahedral particles. From the TEM picture of our particle, we measured the lattice parameter $(a)$ of the FCC lattice to be $3.776 \AA$. According to the literature ${ }^{52}$, the number of total atoms $\left(N_{\mathrm{T}}\right)$ and the number of surface atoms $\left(N_{\mathrm{S}}\right)$ in a perfect fcc cuboctahedral particle vary, respectively, as a function of $16 m^{3}-33 m^{2}+24 m-6$ and $30 m^{2}-60 m+32$ with variable $m$ which is the number of atoms lying on each equivalent edge of the particle. Thus, the diameter of a sphere with a volume equal to $N_{\mathrm{T}}$ atoms can be expressed as $d=\sqrt[3]{\frac{3}{2 \pi} N_{T}} \cdot a$. Consequently, we estimated that a $21.8 \mathrm{~nm}$ particle would contain a total of 403,014 atoms (correspondingly, $m=30$ ) in which 25,232 atoms are on the surface, leading to a surface/volume ratio of about $6.26 \%$. The surface metal atoms of Ru catalysts were obtained by referring the literature ${ }^{26}$.

Modeling and simulation. The thermodynamic properties of $\mathrm{HEA}-\mathrm{Co}_{\mathrm{x}} \mathrm{Mo}_{\mathrm{y}}$ are also checked by the calculations. Taking HEA- $\mathrm{Co}_{25} \mathrm{Mo}_{45}$ as the example, we applied the established procedures to calculate the thermodynamic properties of HEA- $\mathrm{Co}_{25} \mathrm{Mo}_{45}$ alloy based on available empirical data of the atomic size of constituents, formation enthalpy of binary alloy combinations, configuration entropy of the ideal solutions. Specifically, we evaluated a parameter $(\delta)$ gauging the atomic size difference in the alloys as $\delta=\sqrt{\sum_{i=1}^{n} C_{i}\left(1-\frac{r_{i}}{\bar{r}}\right)}\left(C_{i}\right.$ is the atomic percentage of the $i$ th component, $r_{i}$ is the atomic radius of the $i$ th component which can be obtained in the reference $53, \bar{r}=\sum_{i=1}^{n} C_{i} r_{i}$ is the average atomic radius), the enthalpy of mixing of the alloy as $\Delta H_{\text {mix }}=\sum_{i=1, j>i}^{n} \Omega_{i j} C_{i} C_{j}$ $\left(\Omega_{i j}=4 \Delta H_{\mathrm{AB}}^{\mathrm{mix}}\right.$ is the regular solution interaction parameter between the ith and $\mathrm{jth}$ elements, $\Delta H_{A B}^{\text {mix }}$ is the enthalpy of mixing of binary liquid alloys which are obtained in the reference 54, and the entropy of mixing of the n-element regular solution $\Delta S_{\text {mix }}=-R \sum_{i=1}^{n} C_{i} \ln C_{i}(R$ is gas constant).

From the survey of those bulk multi-component alloys to form solid-solution HEAs, it has been found that the formation of HEA most often requires: $\delta \leq 6.6 \%$ and $-11.6<\Delta H_{\text {mix }}<3.2\left(\mathrm{~kJ} \mathrm{~mol}^{-1}\right)^{45,46}$. In this work, we have calculated that HEA- $\mathrm{Co}_{25} \mathrm{Mo}_{45}$ has $\delta=5.4 \%, \Delta H_{\text {mix }}=0.65\left(\mathrm{~kJ} \mathrm{~mol}^{-1}\right)$, and $\left.\Delta S_{\text {mix }}=11.6\left(\mathrm{~J}(\mathrm{~K} \mathrm{~mol})^{-1}\right)\right)$. Hence, we predict that HEA- $\mathrm{Co}_{25} \mathrm{Mo}_{45}$ should form solid-solution HEA particles. The atomic interaction energy of HEA-Co $\mathrm{Mo}_{y}$ system is evaluated within the framework of the second nearest neighbor Modified Embedded Atom Method (MEAM) ${ }^{55,56}$. The parameters of the MEAM potentials for pure metal $\mathrm{Fe}, \mathrm{Co}, \mathrm{Ni}, \mathrm{Cu}$, and $\mathrm{Mo}$ are taken from references ${ }^{57-59}$. The cross potentials between different metals are developed by fitting the MEAM predictions of the enthalpy of formation and the lattice constants of binary and quaternary alloys against the predictions from the density functional theory (DFT) calculations. All the DFT calculations are carried out using the plane wave basis set and projector augmented wave method and Perdew-Burke-Ernzerhof (PBE) exchange-correlation functional as implemented in the Vienna Ab-initio Simulation Package (VASP) ${ }^{60-62}$. The energy cutoff is set to $500 \mathrm{eV}$ for the plane wave expansion, and the Brillouin zone is sampled by a Monkhorst-Pack k-point mesh of $11 \times 11 \times 11$ for the alloy systems $s^{63}$. As presented in Table S1, the MEAM predictions reproduce well the DFT calculation results.

A Monte Carlo (MC) simulation method based on the Metropolis algorithm ${ }^{64}$ is employed to sample the atomic configurations of HEA- $\mathrm{Co}_{x} \mathrm{Mo}_{y}$ nanoparticle in canonical ensemble ${ }^{65,66}$. Starting from a random atomic configuration, a series of MC trial steps are attempted by performing either of the following two configuration changes: (1) Small displacement of a randomly selects atom along a randomly selected direction, which accounts for the relaxation and local atomic vibration processes. The magnitude of the small displacement is in the range of $(0$, $0.02 \AA)$. (2) Swapping the position of two atoms with different element types, which represents the ling-range diffusion process in the modeled system.

At given temperature $T$, the probability $(p)$ to retain the trial configuration is calculated according to Boltzmann distribution with $p=\min \left[1, \exp \left(-\frac{\Delta E}{k_{B} T}\right)\right]$, where $\Delta E$ is the total energy change of the alloy system, due to the configuration variation, calculated from the MEAM potentials and $k_{B}$ is the Boltzmann constant.

In each MC simulation, 10 million MC iterations are performed to evaluate the atomic distribution of the nanoparticles, in which the probability of vibrational tria steps (operation 1 ) is set to $99.9 \%$ and the rest steps $(0.1 \%)$ were assigned to the long-range diffusion operation (operation 2). Thus, we are modeling the equilibrium structures of alloy particles under the situation in which long-range diffusion processes are dynamically slow and limited.

\section{Data availability}

The data that support the figures in this work and other findings corresponding to this study are available from the corresponding authors upon reasonable request.

Received: 15 April 2019 Accepted: 29 July 2019

Published online: 05 September 2019

\section{References}

1. Schuth, F., Palkovits, R., Schlogl, R. \& Su, D. S. Ammonia as a possible element in an energy infrastructure: catalysts for ammonia decomposition. Energy Environ. Sci. 5, 6278-6289 (2012).

2. Choudhary, T. V., Sivadinarayana, C. \& Goodman, D. W. Catalytic ammonia decomposition: $\mathrm{CO}_{\mathrm{x}}$-free hydrogen production for fuel cell applications. Catal. Lett. 72, 197-201 (2001).

3. Yin, S. F., et al. Investigation on the catalysis of $\mathrm{CO}_{\mathrm{x}}$-free hydrogen generation from ammonia. J. Catal. 224, 384-396 (2004).

4. Ganley, J. C., Thomas, F. S., Seebauer, E. G. \& Masel, R. I. A priori catalytic activity correlations: the difficult case of hydrogen production from ammonia. Catal. Lett. 96, 117-122 (2004).

5. Yin, S. F., Xu, B. Q., Zhou, X. P. \& Au, C. T. A mini-review on ammonia decomposition catalysts for on-site generation of hydrogen for fuel cell applications. Appl. Catal. A Gen. 277, 1-9 (2004). 
6. Hansgen, D. A., Vlachos, D. G. \& Chen, J. G. G. Using first principles to predict bimetallic catalysts for the ammonia decomposition reaction. Nat. Chem. 2, 484-489 (2010).

7. Simonsen, S. B., Chakraborty, D., Chorkendorff, I. \& Dahl, S. Alloyed Ni-Fe nanoparticles as catalysts for NH3 decomposition. Appl. Catal. A Gen. 447, 22-31 (2012).

8. Bell, T. E. \& Torrente-Murciano, L. $\mathrm{H}_{2}$ production via ammonia decomposition using non-noble metal catalysts: a review. Top. Catal. 59, 1438-1457 (2016).

9. Jacobsen, C. J. H. Novel class of ammonia synthesis catalysts. Chem. Commun. 12, 1057-1058 (2000).

10. Jacobsen, C. J. H., et al. Catalyst design by interpolation in the periodic table: Bimetallic ammonia synthesis catalysts. J. Am. Chem. Soc. 123, 8404-8405 (2001).

11. Boisen, A., Dahl, S. \& Jacobsen, C. J. H. Promotion of binary nitride catalysts: Isothermal N-2 adsorption, microkinetic model, and catalytic ammonia synthesis activity. J. Catal. 208, 180-186 (2002).

12. Boisen, A., Dahl, S., Norskov, J. K. \& Christensen, C. H. Why the optimal ammonia synthesis catalyst is not the optimal ammonia decomposition catalyst. J. Catal. 230, 309-312 (2005).

13. Podila, S., et al. Hydrogen production by ammonia decomposition using high surface area $\mathrm{Mo}_{2} \mathrm{~N}$ and $\mathrm{Co}_{3} \mathrm{Mo}_{3} \mathrm{~N}$ catalysts. Catal. Sci. Technol. 6, 1496-1506 (2016).

14. Duan, X.Z., et al. Understanding Co-Mo catalyzed ammonia decomposition: influence of calcination atmosphere and identification of active phase. Chemcatchem 8, 938-945 (2016).

15. Srifa, A., et al. Hydrogen production by ammonia decomposition over Csmodified $\mathrm{Co}_{3} \mathrm{Mo}_{3} \mathrm{~N}$ catalysts. Appl. Catal. B Environ. 218, 1-8 (2017).

16. Yao, Y. G., et al. Shahbazian-Yassar, R., Li J. \& Hu, L.B. Carbothermal shock synthesis of high-entropy-alloy nanoparticles. Science 359, 1489-1494 (2018).

17. Yeh, J. W., et al. Nanostructured high-entropy alloys with multiple principal elements: novel alloy design concepts and outcomes. Adv. Eng. Mater. 6, 299-303 (2004).

18. Cantor, B., Chang, I. T. H., Knight, P. \& Vincent, A. J. B. Microstructural development in equiatomic multicomponent alloys. Mater. Sci. Eng. A 375, 213-218 (2004).

19. Zhang, Y., Zhou, Y. J., Lin, J. P., Chen, G. L. \& Liaw, P. K. Solid-solution phase formation rules for multi-component alloys. Adv. Eng. Mater. 10, 534-538 (2008).

20. Yusenko, K.V., et al. First hexagonal close packed high-entropy alloy with outstanding stability under extreme conditions and electrocatalytic activity for methanol oxidation. Scr. Mater. 138, 22-27 (2017).

21. NIST X-ray Photoelectron Spectroscopy Database, NIST Standard Reference Database Number 20, National Institute of Standards and Technology, Gaithersburg MD, 20899 (2000), https://doi.org/10.18434/T4T88K, (retrieved 17 October 2018).

22. Bligaard, T. \& Norskov, J. K. Ligand effects in heterogeneous catalysis and electrochemistry. Electrochim. Acta 52, 5512-5516 (2007).

23. Sengar, S. K., Mehta, B. R. \& Gupta, G. Charge transfer, lattice distortion, and quantum confinement effects in $\mathrm{Pd}, \mathrm{Cu}$, and $\mathrm{Pd}-\mathrm{Cu}$ nanoparticles; size and alloying induced modifications in binding energy. Appl. Phys. Lett. 98, 193115 (2011).

24. Mukherjee, S., Devaguptapu, S. V., Sviripa, A., Lund, C. R. F. \& Wu, G. Mesoporous $\mathrm{Ru} / \mathrm{MgO}$ prepared by a deposition-precipitation method as highly active catalyst for producing $\mathrm{CO}_{\mathrm{x}}$-free hydrogen from ammonia decomposition. Appl. Catal. B Environ. 211, 167-175 (2017).

25. Mukherjee, S., Devaguptapu, S. V., Sviripa, A., Lund, C. R. F. \& Wu, G. Lowtemperature ammonia decomposition catalysts for hydrogen generation. Appl. Catal. B Environ. 226, 162-181 (2018).

26. Karim, A.M., et al. Correlating particle size and shape of supported $\mathrm{Ru} /$ gamma- $\mathrm{Al}_{2} \mathrm{O}_{3}$ catalysts with $\mathrm{NH} 3$ decomposition activity. J. Am. Chem. Soc. 131, 12230-12239 (2009).

27. Yin, S.F., et al. Carbon nanotubes-supported Ru catalyst for the generation of $\mathrm{CO}_{\mathrm{x}}$-free hydrogen from ammonia. Catal. Today 93-5, 27-38 (2004).

28. Bradford, M. C. J., Fanning, P. E. \& Vannice, M. A. Kinetics of $\mathrm{NH}_{3}$ decomposition over well dispersed Ru. J. Catal. 172, 479-484 (1997).

29. Prasad, V., Karim, A. M., Arya, A. \& Vlachos, D. G. Assessment of overall rate expressions and multiscale, microkinetic model uniqueness via experimental data injection: ammonia decomposition on $\mathrm{Ru}$ /gamma- $\mathrm{Al}_{2} \mathrm{O}_{3}$ for hydrogen production. Ind. Eng. Chem. Res. 48, 5255-5265 (2009).

30. Pacheco, V., et al. Thermal stability of the HfNbTiVZr high-entropy alloy. Inorg. Chem. 58, 811-820 (2019).

31. Hsu, Y. J., Chiang, W. C. \& Wu, J. K. Corrosion behavior of FeCoNiCrCux high-entropy alloys in $3.5 \%$ sodium chloride solution. Mater. Chem. Phys. 92, 112-117 (2005).

32. Chou, Y. L., Yeh, J. W. \& Shih, H. C. The effect of molybdenum on the corrosion behaviour of the high-entropy alloys $\mathrm{Co}_{1.5} \mathrm{CrFeNi}_{1.5} \mathrm{Ti}_{0.5} \mathrm{Mo}_{\mathrm{x}}$ in aqueous environments. Corros. Sci. 52, 2571-2581 (2010).
33. Hellman, A. et al. Ammonia synthesis and decomposition on a Ru-based catalyst modeled by first-principles. Surf. Sci. 603, 1731-1739 (2009).

34. Ulissi, Z., Prasad, V. \& Vlachos, D. G. Effect of multiscale model uncertainty on identification of optimal catalyst properties. J. Catal. 281, 339-344 (2011).

35. Morgan, G. A., Kim, Y. K. \& Yates, J. T. Electron-stimulated dissociation of molecular $\mathrm{N}_{2}$ adsorbed on $\mathrm{Ru}(109)$ : A TPD and IRAS investigation. Surf. Sci. 598, 1-13 (2005).

36. Rosowski, F., Hinrichsen, O., Muhler, M. \& Ertl, G. The temperatureprogrammed desorption of $\mathrm{N}_{2}$ from a $\mathrm{Ru} / \mathrm{MgO}$ catalyst used for ammonia synthesis. Catal. Lett. 36, 229-235 (1996).

37. Ertl, G., Lee, S. B. \& Weiss, M. Kinetics of nitrogen adsorption on Fe(111). Surf. Sci. 114, 515-526 (1982).

38. Alstrup, I., Chorkendorff, I. \& Ullmann, S. The interaction of nitrogen with the (111) surface of iron at low and at elevated pressures. J. Catal. 168, 217-234 (1997).

39. Cvetanović, R. J. \& Amenomiya, Y. Application of a temperature-programmed desorption technique to catalyst studies. Adv. Catal. 17, 103-149 (1967).

40. Guan, S. \& Lin, H. Z. Effect of an iron oxide precursor on the N-2 desorption performance for an ammonia synthesis catalyst. Ind. Eng. Chem. Res. 39, 2891-2895 (2000)

41. Fernández, E. M., et al. Scaling relationships for adsorption energies on transition metal oxide, sulfide, and nitride surfaces. Angew. Chem. Int. Ed. 47, 4683-4686 (2008).

42. Lansford, J. L., Mironenko, A. V. \& Vlachos, D. G. Scaling relationships and theory for vibrational frequencies of adsorbates on transition metal surfaces. Nat. Commun. 8, 1842 (2017).

43. Greeley, J. Theoretical heterogeneous catalysis: scaling relationships and computational catalyst design. Annu. Rev. Chem. Biomol. 7, 605-635 (2016).

44. Yu, L. \& Abild-Pedersen, F. Bond order conservation strategies in catalysis applied to the $\mathrm{NH}_{3}$ decomposition reaction. ACS Catal. 7, 864-871 (2017).

45. Yang, X. \& Zhang, Y. Prediction of high-entropy stabilized solid-solution in multi-component alloys. Mater. Chem. Phys. 132, 233-238 (2012).

46. Guo, S., Hu, Q., Ng, C. \& Liu, C. T. More than entropy in high-entropy alloys: forming solid solutions or amorphous phase. Intermetallics 41, 96-103 (2013).

47. Duan, X. Z., Qian, G., Zhou, X. G., Chen, D. \& Yuan, W. K. MCM-41 supported Co-Mo bimetallic catalysts for enhanced hydrogen production by ammonia decomposition. Chem. Eng. J. 207, 103-108 (2012).

48. Lorenzut, B., Montini, T., Bevilacqua, M. \& Fornasiero, P. FeMo-based catalysts for $\mathrm{H}-2$ production by NH3 decomposition. Appl. Catal. B Environ. 125, 409-417 (2012).

49. Leybo, D.V., et al. Effects of composition and production route on structure and catalytic activity for ammonia decomposition reaction of ternary $\mathrm{Ni}-\mathrm{Mo}$ nitride catalysts. Int. J. Hydrog. Energ. 41, 3854-3860 (2016).

50. Guo, J.P., et al. Lithium imide synergy with $3 \mathrm{~d}$ transition-metal nitrides leading to unprecedented catalytic activities for ammonia decomposition. Angew. Chem. Int. Ed. 54, 2950-2954 (2015).

51. Wang, C.P., et al. Experimental investigation and thermodynamic calculation of the phase equilibria in the Co-Mo-W system. Intermetallics 17, 642-650 (2009).

52. Hardeveld, R. V. \& Hartog, F. The statistics of surface atoms and surface sites on metal crystals. Surf. Sci. 15, 189-230 (1969).

53. Kittel, C., "Introduction to Solid State Physics", 7th edition, John Wiley and Sons, New York 1996.

54. Takeuchi, A. \& Inoue, A. Classification of bulk metallic glasses by atomic size difference, heat of mixing and period of constituent elements and its application to characterization of the main alloying element. Mater. Trans. 46, 2817-2829 (2005)

55. Baskes, M. I. Modified embedded-atom potentials for cubic materials and impurities. Phys. Rev. B 46, 2727-2742 (1992).

56. Lee, B. J. \& Baskes, M. I. Second nearest-neighbor modified embedded-atommethod potential. Phys. Rev. B 62, 8564-8567 (2000).

57. Baskes, M. I. \& Johnson, R. A. Modified embedded atom potentials for Hcp metals. Model Simul. Mater. Sci. Eng. 2, 147-163 (1994).

58. Baskes, M. I. Determination of modified embedded atom method parameters for nickel. Mater. Chem. Phys. 50, 152-158 (1997).

59. Lee, B. J., Baskes, M. I., Kim, H. \& Cho, Y. K. Second nearest-neighbor modified embedded atom method potentials for bcc transition metals. Phys Rev. B 64, 184102 (2001).

60. Kresse, G. \& Hafner, J. Ab initio molecular-dynamics simulation of the liquidmetal-amorphous-semiconductor transition in germanium. Phys. Rev. B 49, 14251-14269 (1994)

61. Kresse, G. \& Furthmuller, J. Efficient iterative schemes for ab initio total-energy calculations using a plane-wave basis set. Phys. Rev. B 54, 11169-11186 (1996).

62. Kresse, G. \& Joubert, D. From ultrasoft pseudopotentials to the projector augmented-wave method. Phys. Rev. B 59, 1758-1775 (1999).

63. Monkhorst, H. J. \& Pack, J. D. Special points for Brillouin-zone integrations. Phys. Rev. B 13, 5188-5192 (1976). 
64. Metropolis, N., Rosenbluth, A. W., Rosenbluth, M. N., Teller, A. H. \& Teller, E. Equation of state calculations by fast computing machines. J. Chem. Phys. 21, 1087-1092 (1953).

65. He, Q. F., Ye, Y. F. \& Yang, Y. The configurational entropy of mixing of metastable random solid solution in complex multicomponent alloys. J. Appl. Phys. 120, 154902 (2016).

66. Wang, G. F., Van Hove, M. A., Ross, P. N. \& Baskes, M. I. Monte Carlo simulations of segregation in Pt-Ni catalyst nanoparticles. J. Chem. Phys. 122, 24706 (2005)

\section{Acknowledgements}

P.X. and C.W. thank the support from the Advanced Research Projects Agency-Energy (ARPA-E), Department of Energy (DOE) and the Petroleum Research Fund, American Chemical Society. The work by Y.Y., T.L. and L.H. was not directly supported by any funding. Y.Y., T. L. and L.H. acknowledge the Maryland Nanocenter, its Surface Analysis Center and AIMLab. R.S.-Y. and Z.H.'s efforts were supported by NSF-DMR Award no. 1809439. Z.L and G.W. gratefully acknowledge the computational resources provided by the University of Pittsburgh Center for Research Computing as well as the Extreme Science and Engineering Discovery Environment (XSEDE), which is supported by National Science Foundation grant number ACI-1053575.

\section{Author contributions}

C.W. and P.X. contributed to the idea and experimental design. P.X. and J.Z. conducted the synthesis of control samples, catalytic studies and materials characterizations. Y.Y. T.L. and L.H. synthesized the HEA and Co-Mo bimetallic nanoparticles. Z.H. and R.S-Y. performed the high-resolution STEM imaging and analysis. Z.L. and G. W. contributed to the computational simulations. All authors contributed to the writing of the manuscript.

\section{Additional information}

Supplementary Information accompanies this paper at https://doi.org/10.1038/s41467019-11848-9.

Competing interests: The authors declare no competing interests.

Reprints and permission information is available online at http://npg.nature.com/ reprintsandpermissions/

Peer review information: Nature Communications thanks the anonymous reviewers for their contribution to the peer review of this work.

Publisher's note: Springer Nature remains neutral with regard to jurisdictional claims in published maps and institutional affiliations.



Open Access This article is licensed under a Creative Commons Attribution 4.0 International License, which permits use, sharing, adaptation, distribution and reproduction in any medium or format, as long as you give appropriate credit to the original author(s) and the source, provide a link to the Creative Commons license, and indicate if changes were made. The images or other third party material in this article are included in the article's Creative Commons license, unless indicated otherwise in a credit line to the material. If material is not included in the article's Creative Commons license and your intended use is not permitted by statutory regulation or exceeds the permitted use, you will need to obtain permission directly from the copyright holder. To view a copy of this license, visit http://creativecommons.org/ licenses/by/4.0/.

(C) The Author(s) 2019 